\title{
Validation of remote-sensing products of sea-ice motion: a case study in the western Arctic Ocean
}

\section{Article \\ Cite this article: Gui $D$, Lei $R$, Pang $X$, Hutchings JK, Zuo G, Zhai M (2020). Validation of remote-sensing products of sea-ice motion: a case study in the western Arctic Ocean. Journal of Glaciology 66(259), 807-821. https:// doi.org/10.1017/jog.2020.49}

Received: 16 February 2020

Revised: 4 June 2020

Accepted: 4 June 2020

First published online: 10 July 2020

\section{Key words:}

Ice drifter; Lagrangian trajectory; remotesensing product; sea-ice motion; spatialtemporal variation; validation

\section{Author for correspondence:}

Ruibo Lei,

E-mail: leiruibo@pric.org.cn (c) The Author(s), 2020. This is an Open Access article, distributed under the terms of the Creative Commons Attribution licence (http:// creativecommons.org/licenses/by/4.0/), which permits unrestricted re-use, distribution, and reproduction in any medium, provided the original work is properly cited.

\author{
Dawei Guil ${ }^{1,2}$, Ruibo Lei ${ }^{1,2}$, Xiaoping Pang ${ }^{1}$, Jennifer K. Hutchings ${ }^{3}$, Guangyu Zuo ${ }^{4}$ \\ and Mengxi Zhai
}

${ }^{1}$ Chinese Antarctic Center of Surveying and Mapping, Wuhan University, Wuhan, China; ${ }^{2}$ MNR Key Laboratory for Polar Science, Polar Research Institute of China, Shanghai, China; ${ }^{3}$ College of Earth Ocean and Atmospheric Sciences, Oregon State University, Corvallis, Oregon, USA and ${ }^{4}$ College of Electrical and Power Engineering, Taiyuan University of Technology, Taiyuan, China

\begin{abstract}
The accuracy of sea-ice motion products provided by the National Snow and Ice Data Center (NSIDC) and the Ocean and Sea Ice Satellite Application Facility (OSI-SAF) was validated with data collected by ice drifters that were deployed in the western Arctic Ocean in 2014 and 2016. Data from both NSIDC and OSI-SAF products exhibited statistically significant $(p<0.001)$ correlation with drifter data. The OSI-SAF product tended to overestimate ice speed, while underestimation was demonstrated for the NSIDC product, especially for the melt season and the marginal ice zone. Monthly Lagrangian trajectories of ice floes were reconstructed using the products. Larger spatial variability in the deviation between NSIDC and drifter trajectories was observed than that of OSI-SAF, and seasonal variability in the deviation for NSIDC was observed. Furthermore, trajectories reconstructed using the NSIDC product were sensitive to variations in sea-ice concentration. The feasibility of using remote-sensing products to characterize sea-ice deformation was assessed by evaluating the distance between two arbitrary positions as estimated by the products. Compared with the OSI-SAF product, relative errors are lower $(<11.6 \%)$, and spatial-temporal resolutions are higher in the NSIDC product, which makes it more suitable for estimating sea-ice deformation.
\end{abstract}

\section{Introduction}

Satellite sensors provide images at various resolutions from which sea-ice motion can be retrieved. Microwave radiometers, e.g. Advanced Microwave Scanning Radiometer Earth Observing System (AMSR-E, succeeded by AMSR2 since 2012), Scanning Multichannel Microwave Radiometer (SMMR, available from 1978 to 1987) and Special Sensor Microwave/Imager (SSM/I, succeeded by SSMIS since 2007), and scatterometers, e.g. Advanced Scatterometer (ASCAT, available from 2007 to present), have relatively coarse resolutions of $\sim 6-75 \mathrm{~km}$; the Synthetic Aperture Radar (SAR) and the Advanced Very High Resolution Radiometer (AVHRR) have resolutions of $0.1-4.0 \mathrm{~km}$ and their images contain more details; however, their spatial coverage is small. Satellite-derived sea-ice motion products are widely used in data assimilation and optimization of model parameterization (Nguyen and others, 2011). Products from the National Snow and Ice Data Center (NSIDC), Centre ERS d'Archivage et de Traitement (CERSAT) and the Ocean and Sea Ice Satellite Application Facility (OSI-SAF) are commonly used because of their spatial coverage and continuity over time. Using in situ measurements from acoustic Doppler current profilers, Rozman and others validated sea-ice motion products obtained over the Laptev Sea (Rozman and others, 2011); with a correlation coefficient $(R)$ of 0.86 between the CERSAT product and in situ measurements, which is higher than the correlation between the OSI-SAF product and in situ measurements $(R=0.63)$. Hwang (2013) compared position data from six different satellite ice motion products with measurements by ice-tethered profilers; with a mean deviation of drift speed of $0.22 \pm 2.47 \mathrm{~km} \mathrm{~d}^{-1}$, errors in the OSI-SAF product are lower than those in the CERSAT product. Sumata and others (2014) conducted a comprehensive evaluation of uncertainties in sea-ice motion products, and calculated Eulerian-based temporal and spatial uncertainty estimates in their intercomparison of monthly-mean drifts from four sea-ice motion products: OSI-SAF, CERSAT, NSIDC and that from Kimura and others (2013); uncertainties in OSI-SAF and NSIDC are smaller than those in the other two products especially in regions with higher ice concentration and lower ice drift speed. However, because of the limited spatial coverage of buoy data for one given year, seasonal and regional variations in the accuracy of sea-ice motion products remain unknown. When sea-ice motion products are assimilated into numerical models, it is essential to understand variations of the accuracy of the products to quantify errors in model output (Rollenhagen and others, 2009).

In this study, we estimated errors in the NSIDC and OSI-SAF sea-ice motion products because of their higher spatial and temporal resolutions and frequency of use compared with other products (Sumata and others, 2014). The NSIDC data over the entire year are available since 1979 and OSI-SAF data for the freezing season are available since 2006. They were 
validated against position data collected by ice drifters deployed in the western Arctic Ocean during the Chinese National Arctic Research Expedition (CHINARE) in the summers of 2014 and 2016. Drifter data cover two entire ice seasons, extend over a large area from the marginal ice zone (MIZ) to the perennial ice zone (PIZ), and are independent data that have not been used to construct the ice motion products. Sea ice in summer 2014 was highly compact and deformed in the western Arctic Ocean (Lei and others, 2017), while that in summer 2016 was anomalously low in compactness relative to 2000-2015 climatology (Petty and others, 2018). As a result, this dataset can be used to assess seasonal and regional variations in the accuracy of sea-ice motion products, as well as the influence of ice conditions on product accuracy.

Sea-ice drift trajectories could be used to identify destination or source areas of sea-ice advection or ice-borne contaminants in the Arctic Ocean (e.g. Krumpen and others, 2016; Peeken and others, 2018; Lei and others, 2020). The ability of remote-sensing products to reconstruct sea-ice drift is essential in the validation of high- resolution Lagrangian sea-ice dynamical models (e.g. Rampal and others, 2016) or estimation of ice advection or flux for a specified section using ice motion products (e.g. Kwok, 2009). Moreover, strain rate of the icefield can be retrieved from Lagrangian trajectories, and can be used to study ice mechanics (Kwok, 2010). Here, we compared ice trajectories reconstructed from remote-sensing products with trajectories of ice drifters; seasonal variability was quantified using the distance between reconstructed and drifter trajectories over the monthly temporal window. Using correlation analysis, the influence of sea-ice concentration and ice drift speed on the accuracy of sea-ice motion products was quantified; the feasibility of using sea-ice motion products to characterize sea-ice deformation was also assessed.

\section{Data and methods}

Sea-ice drift product OSI-405-c from OSI-SAF is derived from aggregated maps of passive microwave (SSM/I, SSMIS and

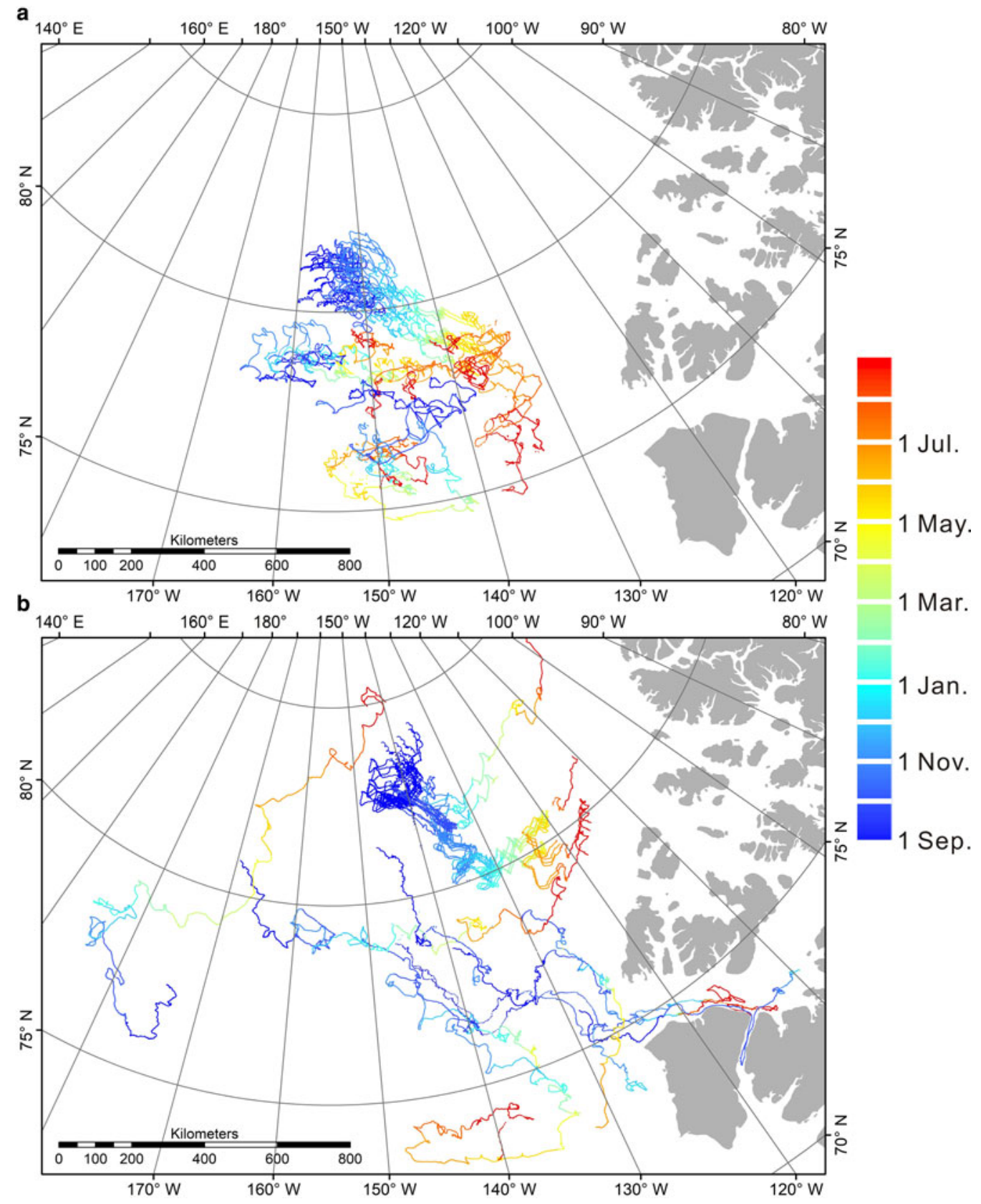

Fig. 1. Trajectories of ice drifters deployed in (a) 2014/15 and (b) 2016/17. 

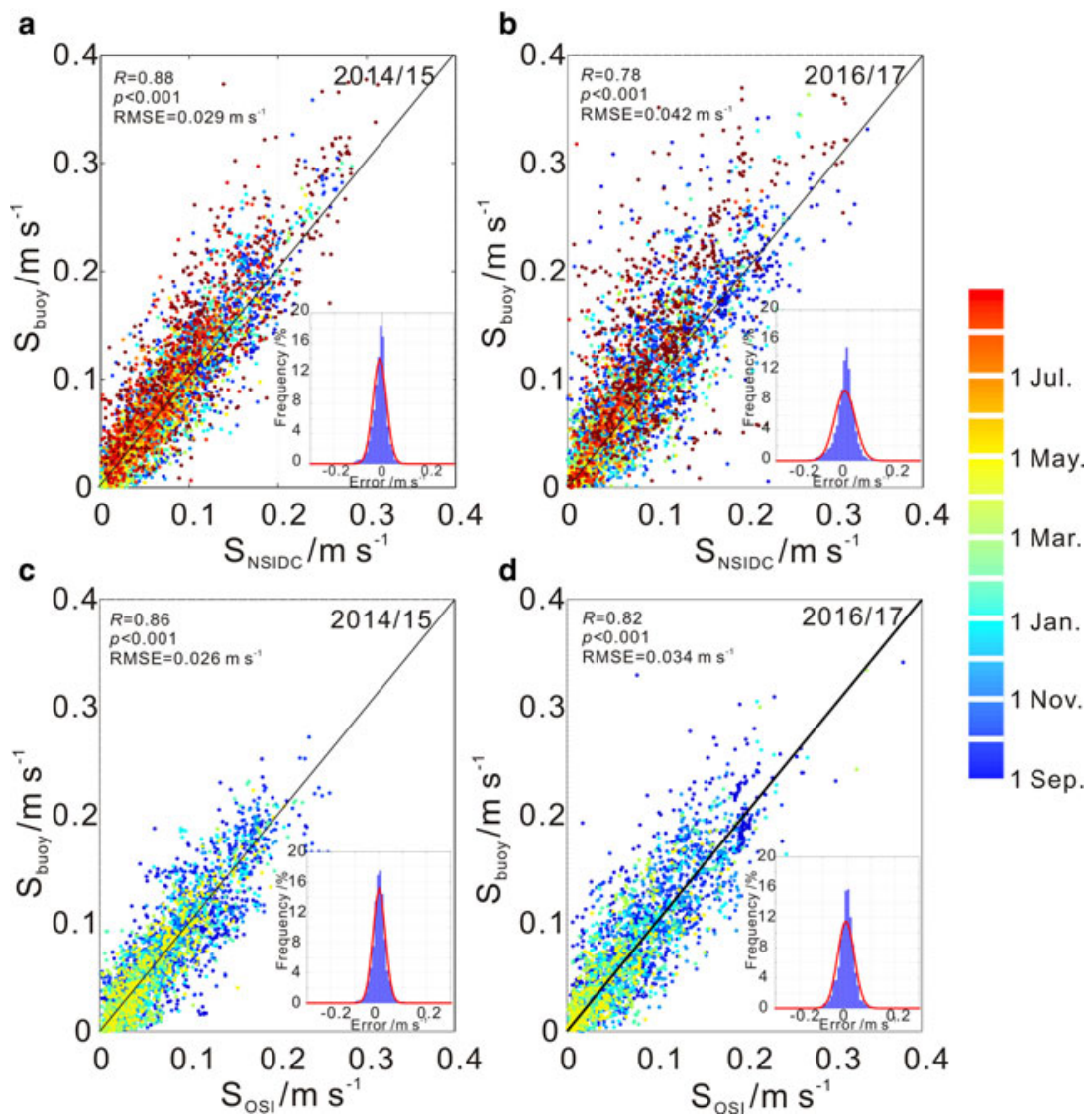

Fig. 2. Correlation between sea-ice drift speed derived from sea-ice motion products and drifter data in (a and c) 2014/15 and ( $b$ and d) 2016/17. Subplot in the bottom-right corner of each panel is the frequency distribution of the error of ice speed with the red line denoting normal distribution.

AMSR2) and scatterometer (ASCAT) sensors. It is available for October to April since 2006 with spatial and temporal resolutions of $62.5 \mathrm{~km}$ and $2 \mathrm{~d}$ on a Polar Stereographic Grid (Lavergne and others, 2010). The Polar Pathfinder Daily $25 \mathrm{~km}$ EASE-Grid Sea Ice Motion Vectors Version 4 dataset from NSIDC is derived from a wide variety of sensors (AVHRR, AMSR-E, SMMR, SSM/I, SSMIS) and data from the International Arctic Buoy Program (IABP), and surface winds from NCEP/NCAR Reanalysis. It is a year-round sea-ice motion dataset available from 25 October 1978 to 31 December 2018 with spatial and temporal resolutions of $25 \mathrm{~km}$ and $1 \mathrm{~d}$ (Tschudi and others, 2019). We also used sea-ice concentration derived from the Advanced Microwave Scanning Radiometer 2 (AMSR2) using the Arctic Radiation and Turbulence Interaction STudy (ARTIST) sea-ice (ASI) algorithm (Spreen and others, 2008) to determine ice conditions in the vicinity of ice drifters.

During the CHINARE-2014 in summer 2014 and CHINARE-2016 in summer 2016, 23 and 29 ice drifters equipped with Global Position Systems were deployed on ice floes (Fig. 1). Data from these drifters have not yet been assimilated into any ice motion products, allowing objective validation of satellite-derived products. Drifters included Ice Mass Balance Buoys (IMBs; Richter-Menge and others, 2006), Ice Surface Velocity Program (iSVP) buoys manufactured by the Canadian company MetOcean and Snow and Ice Mass Balance Arrays (SIMBAs) manufactured by the Scottish Association for Marine Science (Jackson and others, 2013). Sampling interval was half-hourly for SIMBAs and hourly for other drifters, and positioning error was $<10 \mathrm{~m}$. To evaluate the accuracy of sea-ice motion products over a full annual cycle, data from 1 September of the year of deployment to 31 August of the following year were used. In the narrow channel of the Amundsen Gulf, the influence of the coastal constraint resulted in an absence of remote-sensing data; therefore, the data when the ice drifters drifting into this region were excluded from the study. Nine drifters operated through the entire annual cycle of 2014/15 while seven operated through 2016/17. Fifteen ice drifters (or more than 50\%) that were deployed in 2016 survived into the melt season of 2017. In 2014/15, drifters traveled approximately clockwise, indicating an anticyclonic circulation that is in line with climatological mean circulation (Rigor and others, 2002). A different scenario was observed in 2016/17, especially after March 2017, with northeastward flow dominating north of $80^{\circ} \mathrm{N}$, indicating cyclonic circulation.

Sea-ice motion vectors of each product were bilinearly interpolated on to the daily mean positions of the drifters. To be consistent with NSIDC and OSI-SAF, drifter speed at successive positions was calculated as the quotient of displacement along the $x$ - and $y$-axis of projected coordinates and the time taken to make the displacement (Eqns (1) and (2)). Zonal (u) and meridional $(v)$ components of ice velocity were obtained by projecting velocity components on to the coordinates. Sea-ice drift speed $(S)$ was calculated following Eqn (3):

$$
\begin{gathered}
u\left(X_{i+1}, T_{i+1}\right)=\frac{x_{i+1}-x_{i}}{t_{i+1}-t_{i}}(i=1,2,3 \ldots \ldots), \\
v\left(Y_{i+1}, T_{i+1}\right)=\frac{y_{i+1}-y_{i}}{t_{i+1}-t_{i}}(i=1,2,3 \ldots \ldots), \\
S_{i}=\sqrt{u_{i}^{2}+v_{i}^{2}}(i=1,2,3 \ldots \ldots) .
\end{gathered}
$$

Ice drift derived from remote-sensing products was compared with that from drifter measurements to estimate the accuracy of 


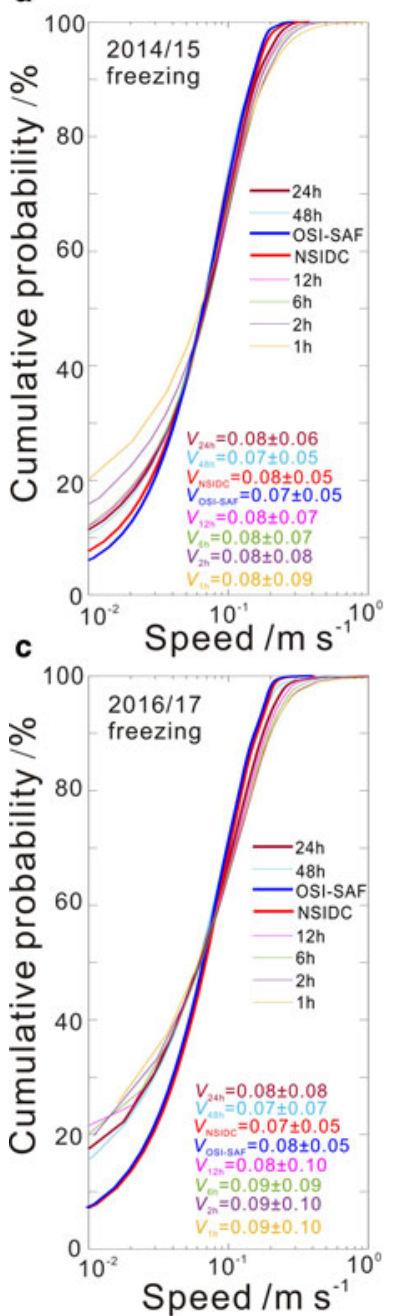

b

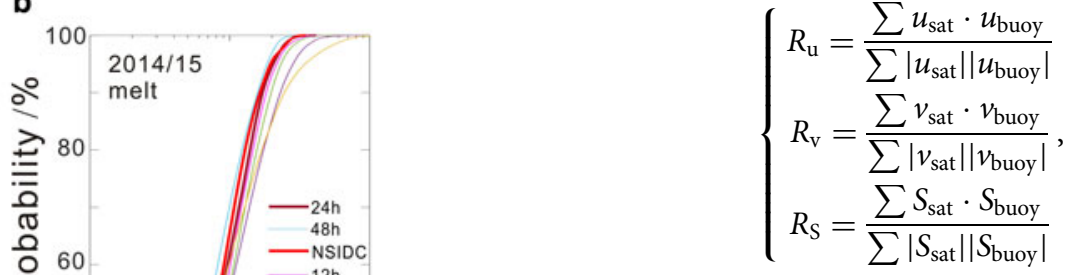

where $d_{s}$ is the absolute error of ice speed, $d_{u}$ and $d_{v}$ are the absolute errors of zonal and meridional components of ice velocity, $\Delta E_{\mathrm{s}}$ is the relative error of speed, $R_{\mathrm{s}}$ is the correlation coefficient between speeds from sea-ice products and drifter measurements, $R_{\mathrm{u}}$ and $R_{\mathrm{v}}$ are the correlation coefficient between zonal and meridional components of ice velocity from sea-ice products and drifter measurements. Statistical significance of correlation coefficients was evaluated using the $t$-test.

Lagrangian trajectories over a temporal window of 1 month were reconstructed from drifter positions on the first day of each month using ice motion products. Validity of the trajectories was evaluated by calculating the Euclidean distance, $D_{\mathrm{e}}$, between the position estimated from remote-sensing products and that measured by drifters:

$$
D_{\mathrm{e}}=\sqrt{\left(x_{i+1}-x_{i}\right)^{2}+\left(y_{i+1}-y_{i}\right)^{2}}(i=1,2,3 \ldots \ldots) .
$$

The geometrical similarity of the trajectories, which accounts for the orientation of ice trajectories (Magdy and others, 2015), was also assessed. Different from $D_{\mathrm{e}}$, the cosine distance, $D_{\mathrm{c}}$, was calculated from the coordinate vector of the positions estimated by remote-sensing products $\left(Q_{\text {sat }}\right)$ and that of the positions measured by drifters $\left(Q_{\text {buoy }}\right)$ using Eqn (8):

$$
D_{\mathrm{c}}=1-\frac{\overrightarrow{Q_{\text {sat }}} \cdot \overrightarrow{Q_{\text {buoy }}}}{\left\|\overrightarrow{Q_{\text {sat }}}\right\|\left\|\overrightarrow{Q_{\text {buoy }}}\right\|},
$$

Fig. 3. Cumulative probabilities of sea-ice drift speed $(V)$ derived from sea-ice motion products and drifter data with different sampling intervals for ( $a$ and b) 2014/15 and (c and d) 2016/17 in different seasons. Numbers at the bottom-right corner of each panel indicate mean values and std dev. of ice speed.

remote-sensing products:

$$
\left\{\begin{array}{c}
\mathrm{d}_{\mathrm{S}}=\left|S_{\text {buoy }}-S_{\text {sat }}\right| \\
\mathrm{d}_{\mathrm{u}}=\left|u_{\text {buoy }}-u_{\text {sat }}\right|, \\
\mathrm{d}_{\mathrm{v}}=\left|v_{\text {buoy }}-v_{\text {sat }}\right|
\end{array}\right.
$$

$$
\Delta E_{\mathrm{S}}=\frac{S_{\text {sat }}-S_{\text {buoy }}}{S_{\text {buoy }}}
$$

where $\quad \overrightarrow{Q_{\mathrm{sat}}}=\left(x_{\mathrm{sat}}(i), y_{\mathrm{sat}}(i)\right)(i=1,2,3 \ldots \ldots) \quad$ and $Q_{\text {buoy }}=\left(x_{\text {buoy }}(i), y_{\text {buoy }}(i)\right)(i=1,2,3 \ldots \ldots)$ denote the vector sequence of positions estimated from remote-sensing products and that from drifter measurements, respectively. The ratio of the dot product of $Q_{\text {sat }}$ and $Q_{b u o y}$ to the norm of $Q_{\text {sat }}$ and $Q_{\text {buoy }}$ represents the cosine similarity of two vectors. The geometrical similarity of ice trajectories increases as the cosine distance approaches zero.

The Euclidean distance between the positions of paired tracking points estimated by sea-ice motion products within 1 month from the location of two arbitrary drifters was calculated, and the relative error, relative to the distance between the positions of drifters, can be obtained. Thus, the accuracy in tracking the distance between ice floes, which is fundamental for the computation of sea-ice deformation rate (e.g. Lei and others, 2020), can be eval-

\begin{tabular}{|c|c|c|c|c|c|c|}
\hline & $\mathrm{d}_{\mathrm{s}}\left(\mathrm{m} \mathrm{s}^{-1}\right)$ & $\Delta E_{\mathrm{s}}$ & $\mathrm{d}_{\mathrm{u}}\left(\mathrm{m} \mathrm{s}^{-1}\right)$ & $\mathrm{d}_{\mathrm{v}}\left(\mathrm{m} \mathrm{s}^{-1}\right)$ & $R_{\mathrm{u}}$ & $R_{\mathrm{v}}$ \\
\hline NSDIC 2014, freezing season & $0.019(0.018)$ & $-2 \%(47 \%)$ & $0.02(0.02)$ & $0.019(0.019)$ & 0.93 & 0.93 \\
\hline NSDIC 2014, melt season & $0.027(0.021)$ & $-10 \%(45 \%)$ & $0.026(0.022)$ & $0.024(0.019)$ & 0.93 & 0.92 \\
\hline NSIDC 2016, freezing season & $0.028(0.033)$ & $-0.6 \%(66 \%)$ & $0.027(0.032)$ & $0.026(0.027)$ & 0.86 & 0.88 \\
\hline NSIDC 2016, melt season & $0.038(0.042)$ & $-7.2 \%(69 \%)$ & $0.034(0.04)$ & $0.031(0.031)$ & 0.82 & 0.88 \\
\hline OSI-SAF 2014, freezing season & $0.02(0.017)$ & $12 \%(70 \%)$ & $0.019(0.018)$ & $0.021(0.019)$ & 0.91 & 0.9 \\
\hline OSI-SAF 2016, freezing season & $0.027(0.026)$ & $4 \%(57 \%)$ & $0.024(0.021)$ & $0.022(0.026)$ & 0.9 & 0.86 \\
\hline
\end{tabular}
uated. This relative error was used to assess the ability of sea-ice motion products to characterize sea-ice deformation.

Table 1. Error statistics of sea-ice drift speed derived from sea-ice motion products relative to drifter measurements

Numbers in parentheses denote std dev. 

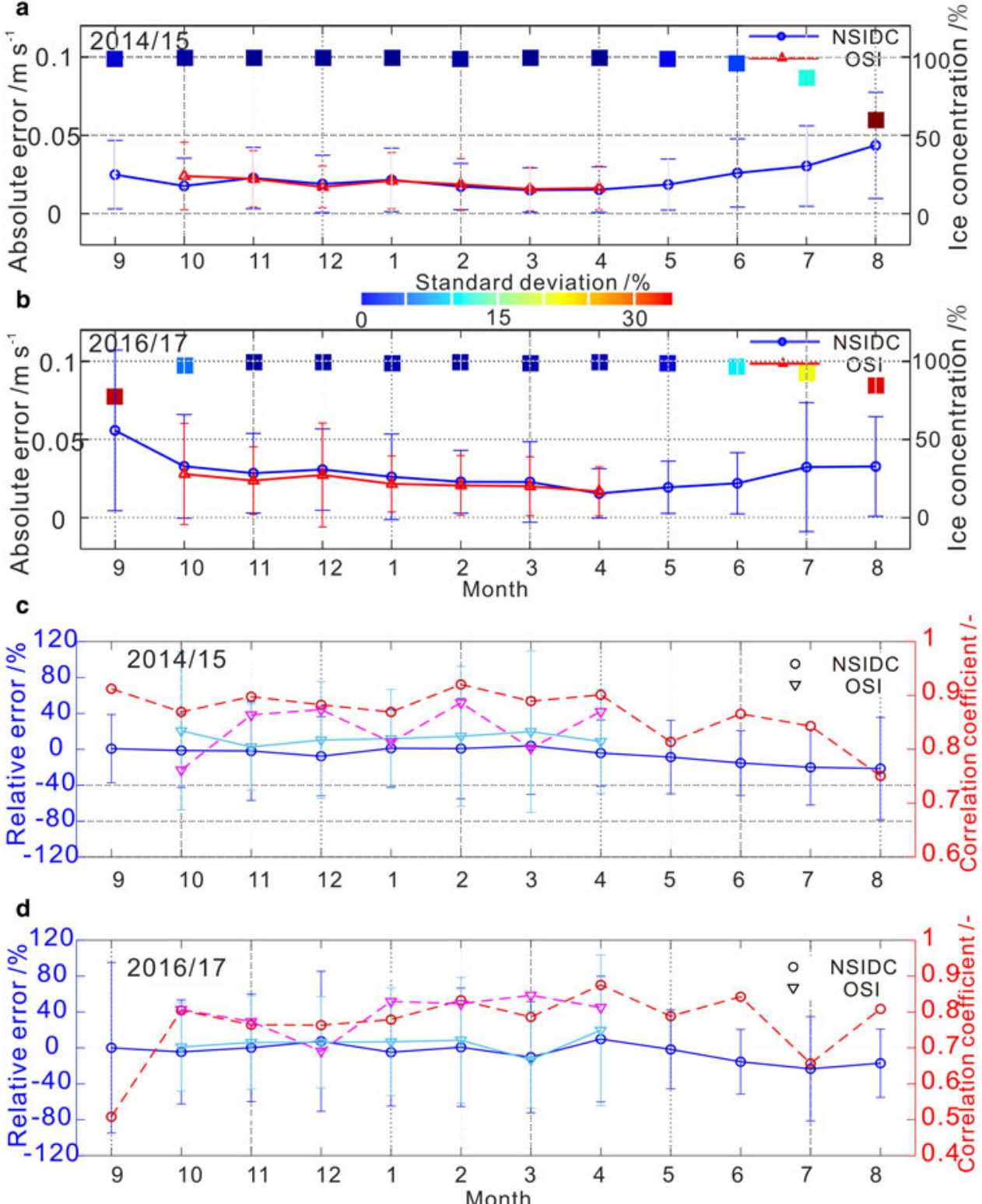

Fig. 4. ( $a$ and b) Monthly mean absolute error of sea-ice drift speed derived from ice motion products relative to drifter measurements for (a) 2014/15 and (b) 2016/ 17; std dev. is indicated by error bars; squares denote monthly sea-ice concentration in the vicinity of drifters; color of square denotes std dev.. (c and d) Relative error (solid line) and correlation coefficient (dashed line) of monthly mean sea-ice drift speed from sea-ice motion products with respect to drifter measurements for (c) 2014/15 and (d) 2016/17; std dev. is indicated by error bars.

\section{Results}

\section{Overall comparison}

To compare sea-ice drift speeds derived from sea-ice motion products with those from drifters, drifter data were downsampled to $1 \mathrm{~d}$ to be consistent with NSIDC and $2 \mathrm{~d}$ for OSI-SAF. Correlations between ice drift speeds derived from drifter and NSIDC or OSI-SAF in 2014/15 and 2016/17 are shown in Figure 2. Generally, both products demonstrated statistically significant high correlations with drifter data. Correlation coefficient $(R)$ for NSIDC through the whole ice season in 2014/15 was 0.88 , which is statistically significant at the $99.9 \%$ level $(p<0.001)$; root mean square error (RMSE) was $0.029 \mathrm{~m} \mathrm{~s}^{-1}$. For the freezing season (October to April), $R$ was $0.91(p<0.001)$, which was $0.89(p<0.001)$ for the melt season (May to September). During the freezing season of $2014 / 15, R$ for OSI-SAF was 0.86 $(p<0.001)$ with RMSE of $0.026 \mathrm{~m} \mathrm{~s}^{-1}$. Correlation coefficients were lower in $2016 / 17$ than in 2014/15. For collocated pairs of data points, overall $R$ between NSIDC and drifter data was 0.78 $(p<0.001)$ with RMSE of $0.042 \mathrm{~m} \mathrm{~s}^{-1} ; R$ in the melt season was $0.76(p<0.001)$, and was $0.78(p<0.001)$ in the freezing season, which were both smaller than $R$ of OSI-SAF in the freezing season (0.82), which implies the NSIDC product is more sensitive to changes in ice conditions. Our results are comparable with those from Sumata (2014) obtained by comparing monthly mean sea-ice drift speeds with data collected by IABP buoys. Error distribution of NSIDC drift speed was wider and had a smaller kurtosis in 2016 than in 2014, indicating larger uncertainties in sea-ice drift speed under conditions of lower sea-ice concentration.

Downsampling smooths over details in sea-ice drift measured by ice drifters, e.g. the semidiurnal inertial ice meander due to the Coriolis force (Lei and others, 2016). Thus, ice drift speed could be underestimated by Eqns (1) and (2), especially for the OSI-SAF because of its coarser temporal resolution. Cumulative probabilities of drift speed derived from drifter data with different sampling intervals are shown in Figure 3. Mean ice speed decreased with increasing sampling interval during both seasons of 2014/15 

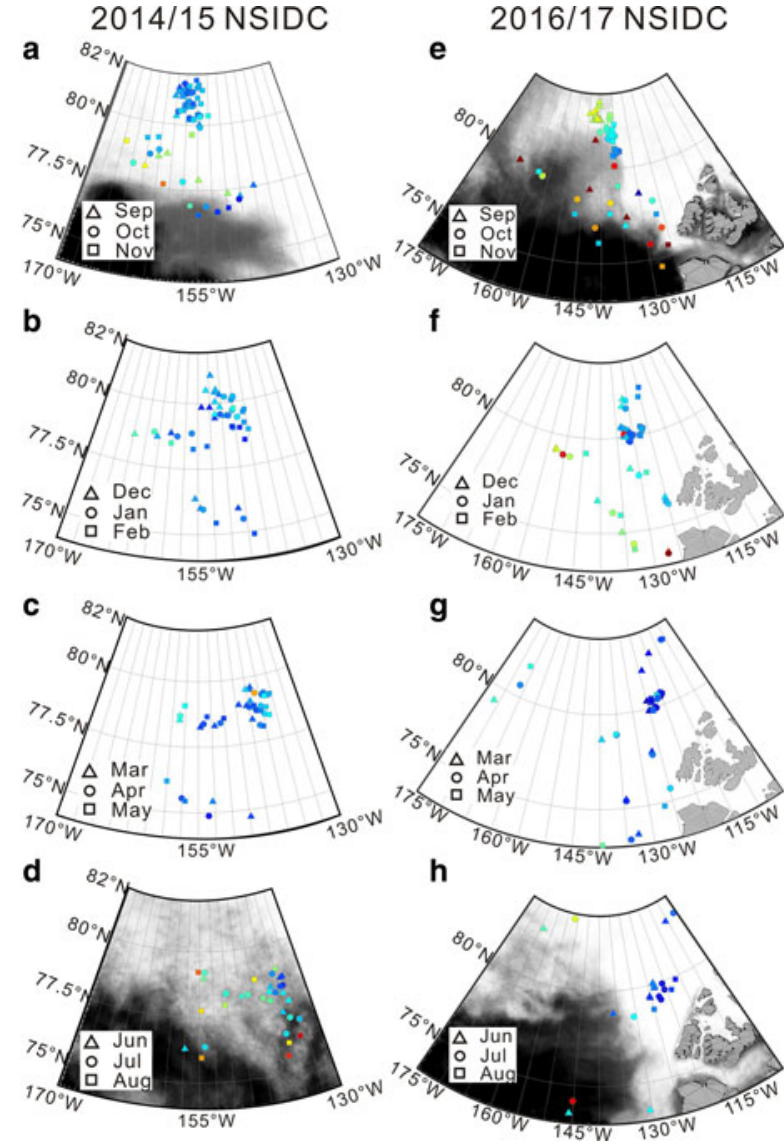
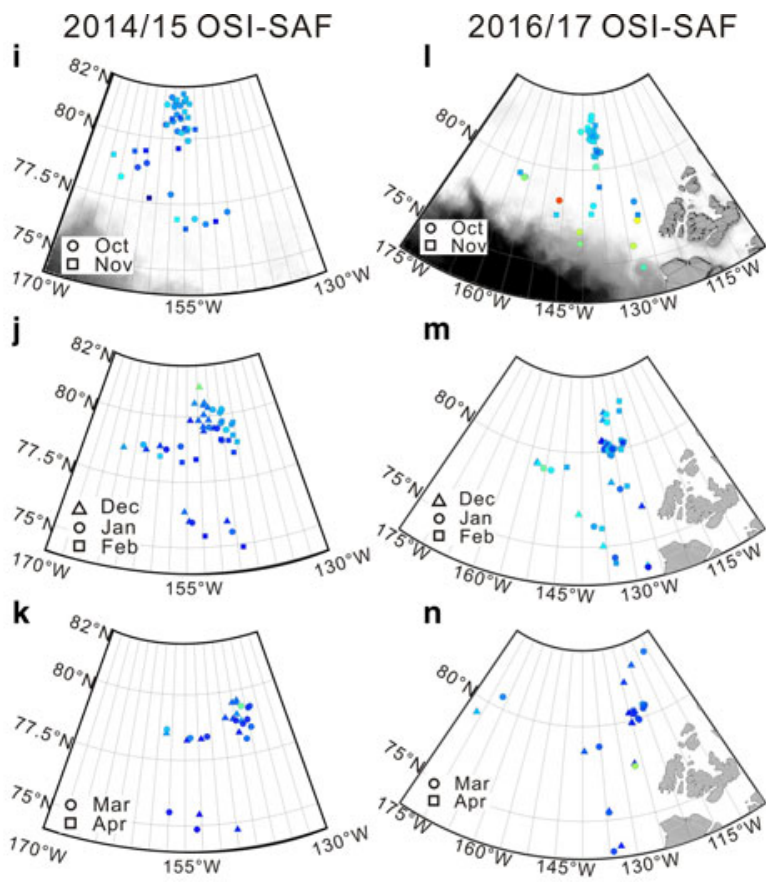

m

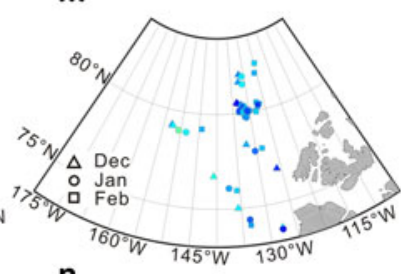

n
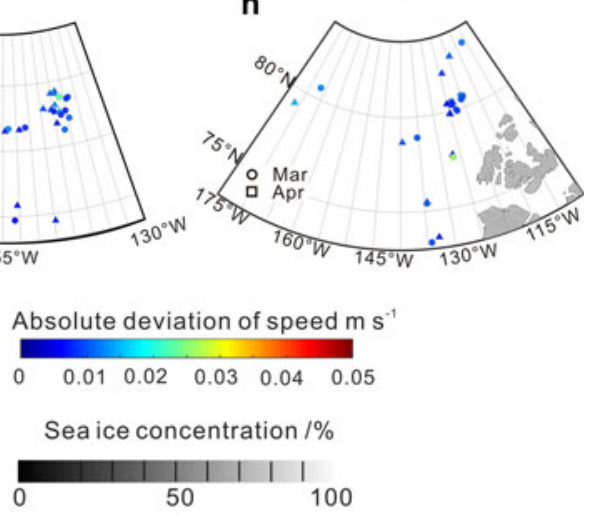

Fig. 5. Spatial distribution of monthly absolute error of ice speed derived (a-d and e-h) from NSIDC and (i-k and l-n) from OSI-SAF relative to drifter data. Gray shading indicates monthly sea-ice concentration from daily AMSR-2 product for (a) September 2014, (d) August 2015, (e) September 2016, (h) August 2017, (i) October 2014 and (l) October 2016.

and 2016/17. Compared with mean ice speed from drifter data at 12 $\mathrm{h}$ resolution, both NSIDC and OSI-SAF speeds are lower by 25 and $30 \%$, respectively. Absolute errors $\left(\mathrm{d}_{\mathrm{s}}\right)$ of sea-ice motion products indicate small deviations from drifter measurements (Table 1), and mean absolute error was larger in 2016 than in 2014 for both products. Mean absolute error was larger in NSIDC than in OSI-SAF for the freezing season of both years. Relative errors $\left(\Delta E_{\mathrm{s}}\right)$ show that, for the same temporal resolution, NSIDC tended to underestimate drift speed, especially in the melt season. Relative errors of NSIDC were -2 and $-0.6 \%$ for the freezing seasons of 2014 and 2016, and -10 and $-7.2 \%$ for the melt seasons of 2014 and 2016. The OSI-SAF product tended to overestimate drift speed, and relative errors were 12 and $4 \%$ for the freezing seasons of 2014 and 2016, respectively. Variations of zonal and meridional components of sea-ice drift coincided almost exactly for NSIDC and OSI-SAF during our study periods, and the difference between mean absolute errors of zonal $\left(\mathrm{d}_{\mathrm{u}}\right)$ and meridional $\left(\mathrm{d}_{\mathrm{v}}\right)$ components ranged from 0.01 to $0.03 \mathrm{~m} \mathrm{~s}^{-1}$.

\section{Temporal and spatial variations in the accuracy of ice motion products}

For both 2014/15 and 2016/17, monthly absolute errors of NSIDC ice speed (Fig. 4) decreased over autumn (SON) and then stayed at relatively low levels with low std dev. in winter (DJF) and spring (MAM). There was considerable seasonal variation in monthly mean sea-ice concentration in the vicinity of drifters, especially in 2016/17. Minima in absolute error were recorded in March $2015\left(0.015 \mathrm{~m} \mathrm{~s}^{-1}\right)$ and April $2017\left(0.0154 \mathrm{~m} \mathrm{~s}^{-1}\right)$ when Arctic sea-ice thickness approached its annual maximum (e.g. Tilling and others, 2018). Because fracture of ice cover before melt onset leads to an increase in sea-ice drift speed (Olason and Notz, 2014), remote-sensing estimates of sea-ice drift are more accurate in winter than in summer when sea-ice mobility is enhanced, and surface melt increases the difficulty in sea-ice identification. As summer (JJA) approached, absolute error, as well as its std dev., started to increase. Increased std dev. indicates an increase in the spatial difference of error because of the enhanced spatial heterogeneity of ice conditions. In 2014/15, the maximum absolute error of NSIDC was $0.043 \mathrm{~m} \mathrm{~s}^{-1}$ and was recorded in August 2015; in $2016 / 17$, the maximum value of $0.056 \mathrm{~m} \mathrm{~s}^{-1}$ was recorded in September 2016, which exceeded twice of the value recorded in September $2014\left(0.025 \mathrm{~m} \mathrm{~s}^{-1}\right)$. This may be attributed to the anomalously low ice concentration in the vicinity of drifters; in September 2014, average ice concentration in the vicinity of drifters was $98.9 \%$, which was considerably larger than that in September 2016 (89.8\%). For the freezing season, the performance of OSI-SAF was highly consistent with that of NSIDC, and monthly mean absolute errors of sea-ice drift speed were $0.016-0.024 \mathrm{~m}$ $\mathrm{s}^{-1}$ in $2014 / 15$ and $0.017-0.028 \mathrm{~m} \mathrm{~s}^{-1}$ in $2016 / 17$.

In $2014 / 15$, the monthly mean relative error of NSIDC drift speed estimates remained small and stable until April 2015, and then increased, indicating enhanced underestimation of sea-ice drift speed as melt season approached. In contrast, OSI-SAF tended to overestimate drift speed through the entire freezing season, and absolute deviations were larger than those of NSIDC. For autumn and winter 2016/17, NSIDC and OSI-SAF exhibited similar variations in relative error. However, both products estimated a decrease in drift speed from February to March, and underestimated drift speed in March with relative errors of $-10 \%$ (NSIDC) and $-13 \%$ (OSI-SAF). After March, both products uniformly overestimated drift speed with relative errors of $9 \%$ 

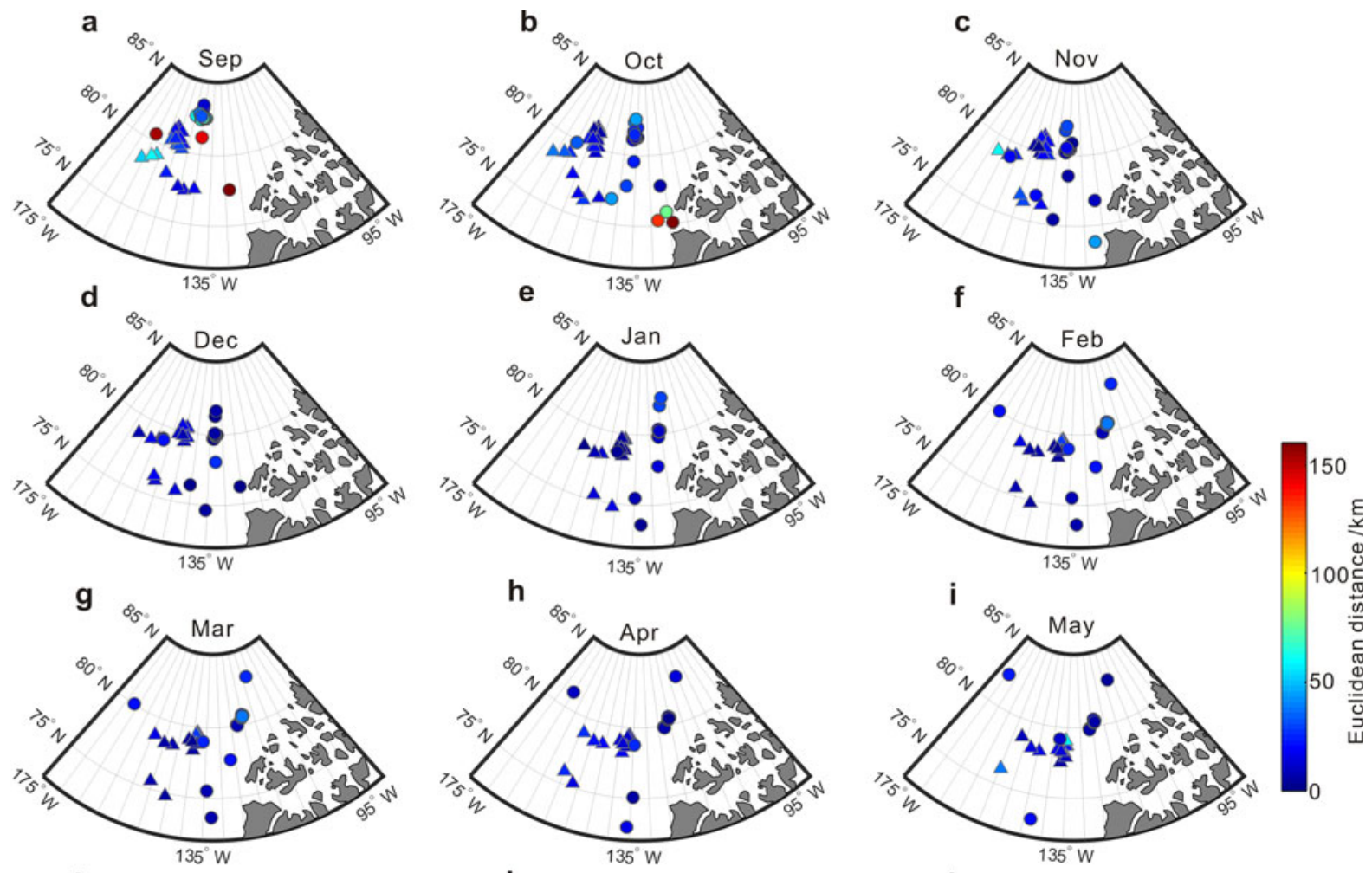

h

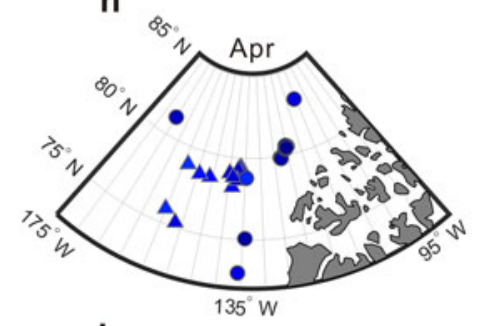

k
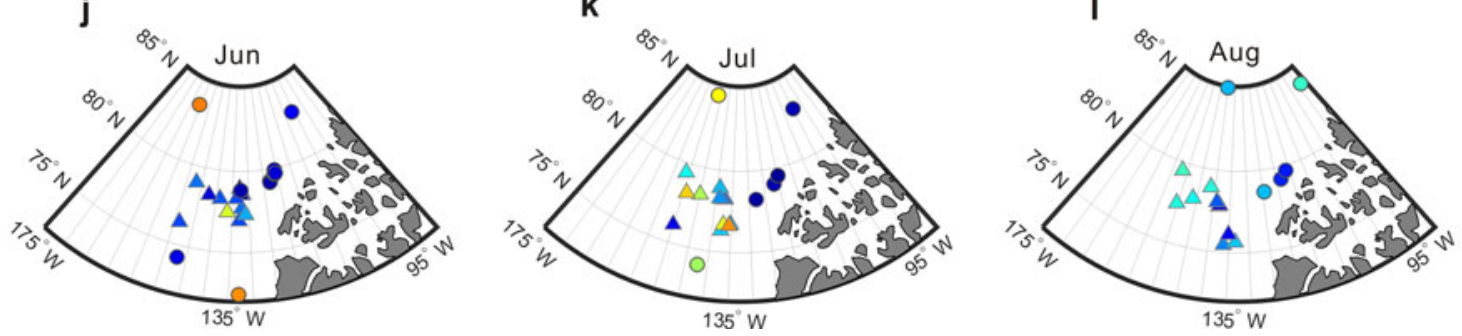

Fig. 6. Spatial distribution of monthly Euclidean distance between positions of drifters and positions estimated from NSIDC. Triangles denote drifters in 2014/15, and circles denote drifters in 2016/17.

(NSIDC) and 19\% (OSI-SAF). This phenomenon might be associated with the low-pressure center that developed over the Barents Sea and extended into the western Arctic between January and March 2017, which enhanced sea-ice drift and deformation rate (Moore and others, 2018). It implies that the ice motion products would underestimate ice speed when ice motion accelerates under storm forcing.

Variation of the monthly correlation coefficient $(R)$ of sea-ice motion products relative to drifter measurements (dashed lines in Figs 4c, d) was generally higher in 2014/15 than in 2016/17. Correlation between OSI-SAF and drifter measurements remained stable with $R$ ranging from 0.69 to 0.88 in the freezing seasons of 2014/15 and 2016/17. For the freezing season of 2014/ $15, R$ of NSIDC $(>0.87)$ was generally higher than that of OSI-SAF. In summer, $R$ decreased when sea ice started to melt, however $R$ remained $>0.75$ and statistically significant at the 99.9\% level even in August 2015. For NSIDC, the minimum value of $R$ (0.51) was recorded in September 2016; $R$ subsequently increased to 0.8 in October 2016; it remained stable from autumn to spring in both years, and decreased considerably from April to July as summer approached. From July to August 2017, an increase in relative error was accompanied by an increase in correlation coefficient. This could be attributed to the drift speed being uniformly underestimated with similar amplitude.

Spatial variability of errors was evaluated by calculating the monthly mean absolute error of sea-ice drift speed (Fig. 5).
Generally, influences of ice conditions on error distribution dominated during melt seasons, while other factors such as wind forcing and coastal constraint could have more influence during freezing seasons. In 2014/15 (Figs 5a-d, 5i-k), drifters were mostly in the region of $75^{\circ} \mathrm{N}-82^{\circ} \mathrm{N}$ and $135^{\circ} \mathrm{W}-165^{\circ} \mathrm{W}$. For NSIDC, a larger error was identified near the MIZ in September $2014\left(0.031 \mathrm{~m} \mathrm{~s}^{-1}\right)$, and where sea-ice concentration was below 60\% in August $2015(0.045$ $\mathrm{m} \mathrm{s}^{-1}$ ). In the freezing season of $2014 / 15$, drifters were in areas of compact ice as the ice edge extended to lower latitudes; the absolute error of NSIDC ranged from 0.004 to $0.036 \mathrm{~m} \mathrm{~s}^{-1}$, which was comparable with that of OSI-SAF $\left(0.004-0.026 \mathrm{~m} \mathrm{~s}^{-1}\right)$.

Similar to 2014 , drifter arrays were located north of $80^{\circ} \mathrm{N}$ in September 2016. However, the mean latitude of the ice edge, defined as the ice concentration threshold of $15 \%$ for the study region at the time of interest, retreated to $78.9^{\circ} \mathrm{N}$, in contrast with that extended to $74.5^{\circ} \mathrm{N}$ in September 2014. Because of lower sea-ice concentration, errors in NSIDC near the MIZ were larger in September 2016 than in September 2014. Mean absolute error in NSIDC in September 2016 was $0.033 \mathrm{~m} \mathrm{~s}^{-1}$, which exceeded twice that in September 2014 $\left(0.016 \mathrm{~m} \mathrm{~s}^{-1}\right)$. There were large differences in absolute error near Banks Island in winter 2016/17 between NSIDC and OSI-SAF estimates (Figs $5 \mathrm{f}, \mathrm{m}$ ), which implies that differences in the temporal resolution of remote-sensing products result in differences in the influence of coastal constraint on ice motion product. Error in NSIDC for December 2016 was $0.041 \mathrm{~m} \mathrm{~s}^{-1}$, which exceeded twice that in OSI-SAF $\left(0.019 \mathrm{~m} \mathrm{~s}^{-1}\right)$; error in NSIDC increased to $0.056 \mathrm{~m} \mathrm{~s}^{-1}$ in 

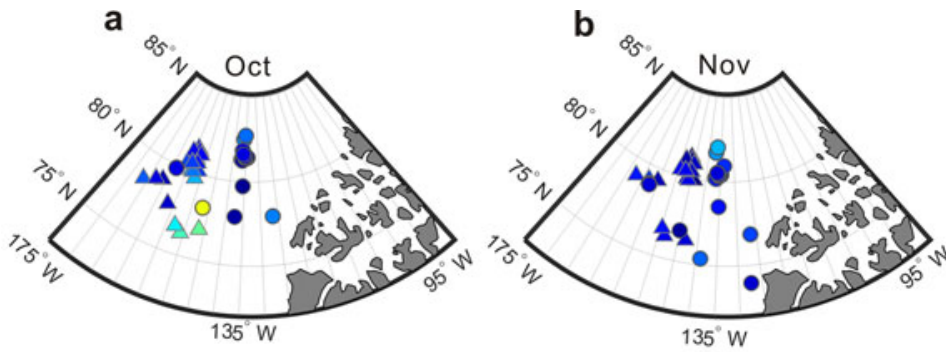

d

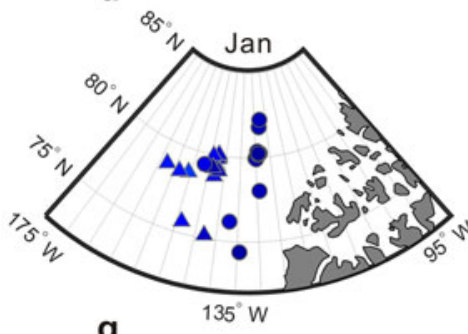

g
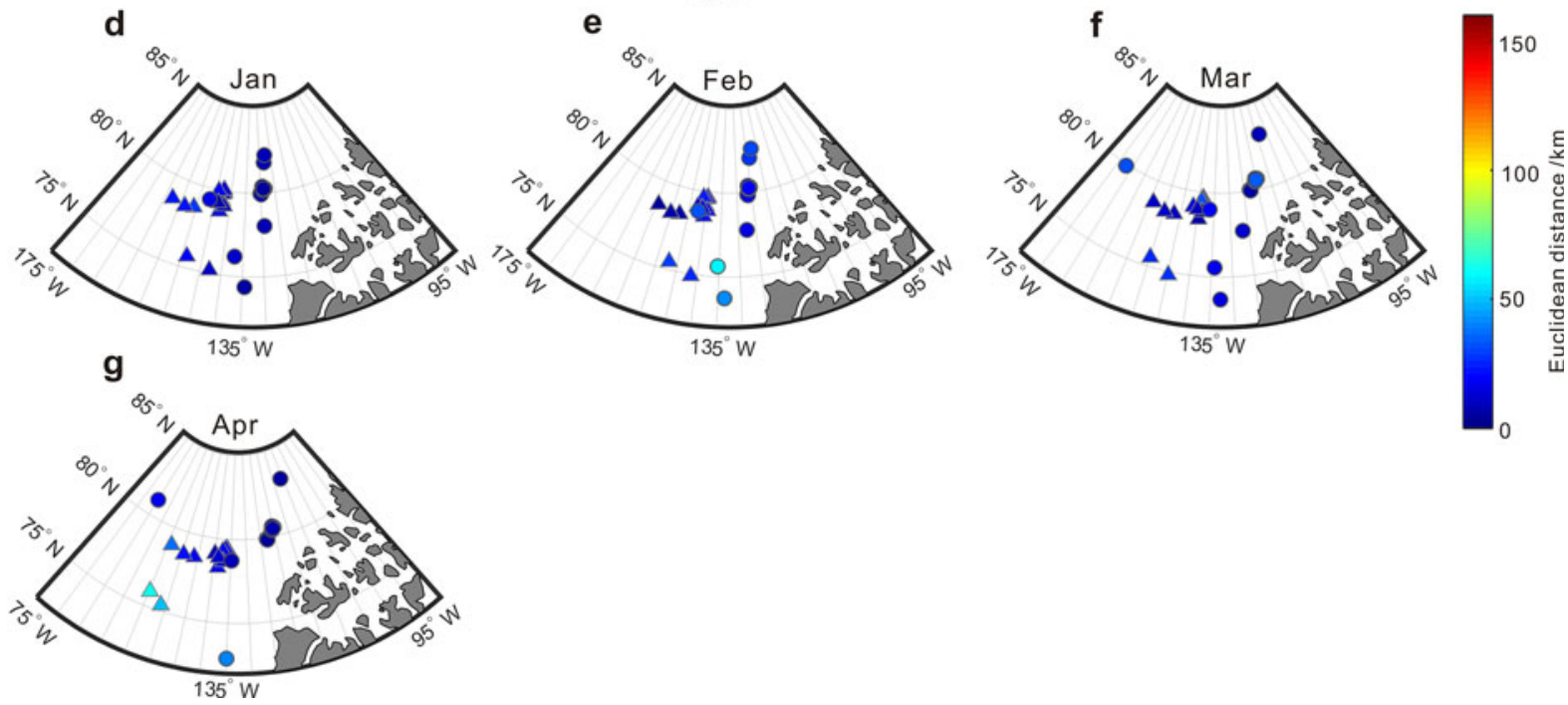

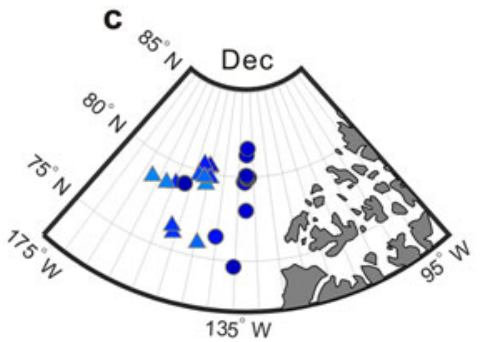

150

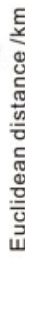

Fig. 7. Same as Figure 6 , but for OSI-SAF.

January 2017, and was ten times larger than that in OSI-SAF $(0.005 \mathrm{~m}$ $\mathrm{s}^{-1}$ ), possibly indicating larger uncertainties in NSIDC estimates close to the shore. Shear deformation of sea ice becomes stronger in coastal areas, and this effect weakens with an increase in temporal and spatial scales. Thus, the influence of sea-ice shear deformation in coastal regions could be reduced in OSI-SAF product because of its lower temporal and spatial resolutions.

\section{The ability of sea-ice motion products to reconstruct sea-ice trajectory}

Using sea-ice motion products, we reconstructed monthly trajectories of sea-ice drift from drifter positions at the beginning of each month. Euclidean distance between final positions of reconstructed trajectories and corresponding drifter trajectories is shown at the final position of each drifter for different months in Figure 6. In 2014/15, distance between drifter position and position from NSIDC reconstructed trajectories varied seasonally. Mean value of monthly Euclidean distance decreased from $11.5 \pm$ $5.4 \mathrm{~km}$ in autumn to $5.4 \pm 1.8 \mathrm{~km}$ in winter, and can be ascribed to decrease in sea-ice mobility. Because OSI-SAF only covers freezing seasons, there were no detectable seasonal variations in monthly Euclidean distance, which was $14.0 \pm 7.6 \mathrm{~km}$ in autumn $(\mathrm{ON}), 14.9 \pm 7.4 \mathrm{~km}$ in winter (DJF) and $12.8 \pm 5.6 \mathrm{~km}$ in spring (MA). In 2016/17, mean Euclidean distance for NSIDC was 24.0 $\pm 15.7 \mathrm{~km}$, which exceeded twice that in autumn 2014 .

Spatial variability of Euclidean distance in NSIDC was larger in melt seasons than in freezing seasons (Fig. 6), which might be attributed to the increased spatial heterogeneity of ice conditions in summer. Euclidean distance was larger in the southern MIZ than in the northern PIZ. In 2014, mean Euclidean distances were $15.6 \pm 0.7$ and $5.9 \pm 1.9 \mathrm{~km}$ north of $80^{\circ} \mathrm{N}$ in September and October, which increased to $28.2 \pm 13$ and $19.2 \pm 8.2 \mathrm{~km}$ south of $80^{\circ} \mathrm{N}$. Anomalously large values of Euclidean distance were identified in the MIZ, where spatial heterogeneity was more marked in autumn 2016 than in autumn 2014. Euclidean distances $>100 \mathrm{~km}$ were recorded south of $82^{\circ} \mathrm{N}$ in September 2016 and south of $80^{\circ}$ $\mathrm{N}$ in October 2016. Mean Euclidean distances for the freezing seasons of 2014 and 2016 were $12.6 \pm 8.9$ and $18.3 \pm 22 \mathrm{~km}$, and were without considerable spatial variability. When sea ice started to melt in summer, Euclidean distance increased generally, especially at lower latitudes, which is consistent with seasonal variations of the uncertainty of sea-ice velocity.

Euclidean distance between drifter positions and OSI-SAF estimates also demonstrated relatively high spatial variability in autumn (Fig. 7). Mean Euclidean distances in the regions north and south of $80^{\circ} \mathrm{N}$ were $17.7 \pm 1.7$ and $32.6 \pm 18.6 \mathrm{~km}$ in October 2014, and $15.6 \pm 9.5$ and $27.2 \pm 13.2 \mathrm{~km}$ in 2016. Mean Euclidean distances were $19.2 \pm 13.0$ and $17.0 \pm 12.7 \mathrm{~km}$ for the freezing seasons of 2014 and 2016, and variability are comparable with those obtained from the NSIDC product for the same period.

Unlike the Euclidean distance, which characterizes the magnitude of position deviation (Pfirman and others, 1997; Lindsay and Stern, 2003), the cosine distance evaluates geometrical similarity between drifter trajectories and trajectories reconstructed from ice motion products (Nakamura and others, 2013). For NSIDC, seasonal variation of cosine distance in 2014 was similar to that of Euclidean distance. However, there was large variability in the cosine distance of NSIDC in 2016/17, which ranged from a mean value of $(6.0 \pm$ $5.1) \times 10^{-4}$ in September 2016 to $(4.2 \pm 3.0) \times 10^{-4}$ in August 2017 . Cosine distance for OSI-SAF was stable without obvious differences between 2 years; maximum and mean values were $2.3 \times 10^{-4}$ and $(6.2 \pm 5.7) \times 10^{-5}$ in $2014 / 15$, and $2.1 \times 10^{-4}$ and $(3.3 \pm 3.3) \times 10^{-5}$ in the freezing season of 2016/17.

In September 2014 and 2016, cosine distances in NSIDC in low latitudes and the MIZ were one order of magnitude greater than those from other locations (Fig. 8). In September 2014, mean cosine distance was $(3.6 \pm 4.2) \times 10^{-4}$ south of $80^{\circ} \mathrm{N}$ and $(13 \pm 1.1) \times 10^{-5}$ north of $80^{\circ} \mathrm{N}$. In October, the magnitude of cosine distance in 2014 was comparable with that in 2016 except 

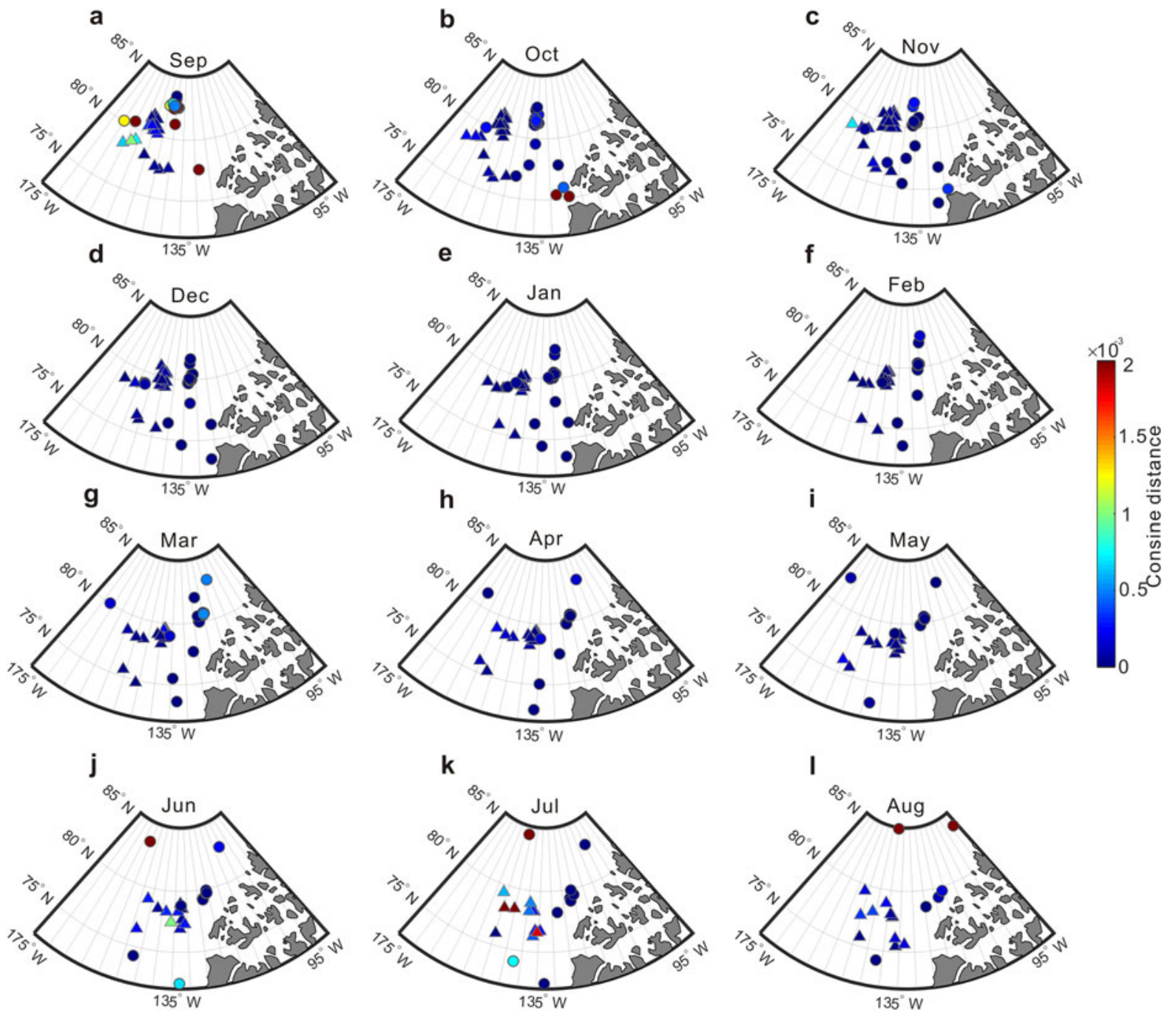

Fig. 8. Spatial distribution of monthly cosine distance between positions of drifters and positions estimated from NSIDC. Triangles denote drifters in $2014 / 15$, and circles denote drifters in 2016/17.
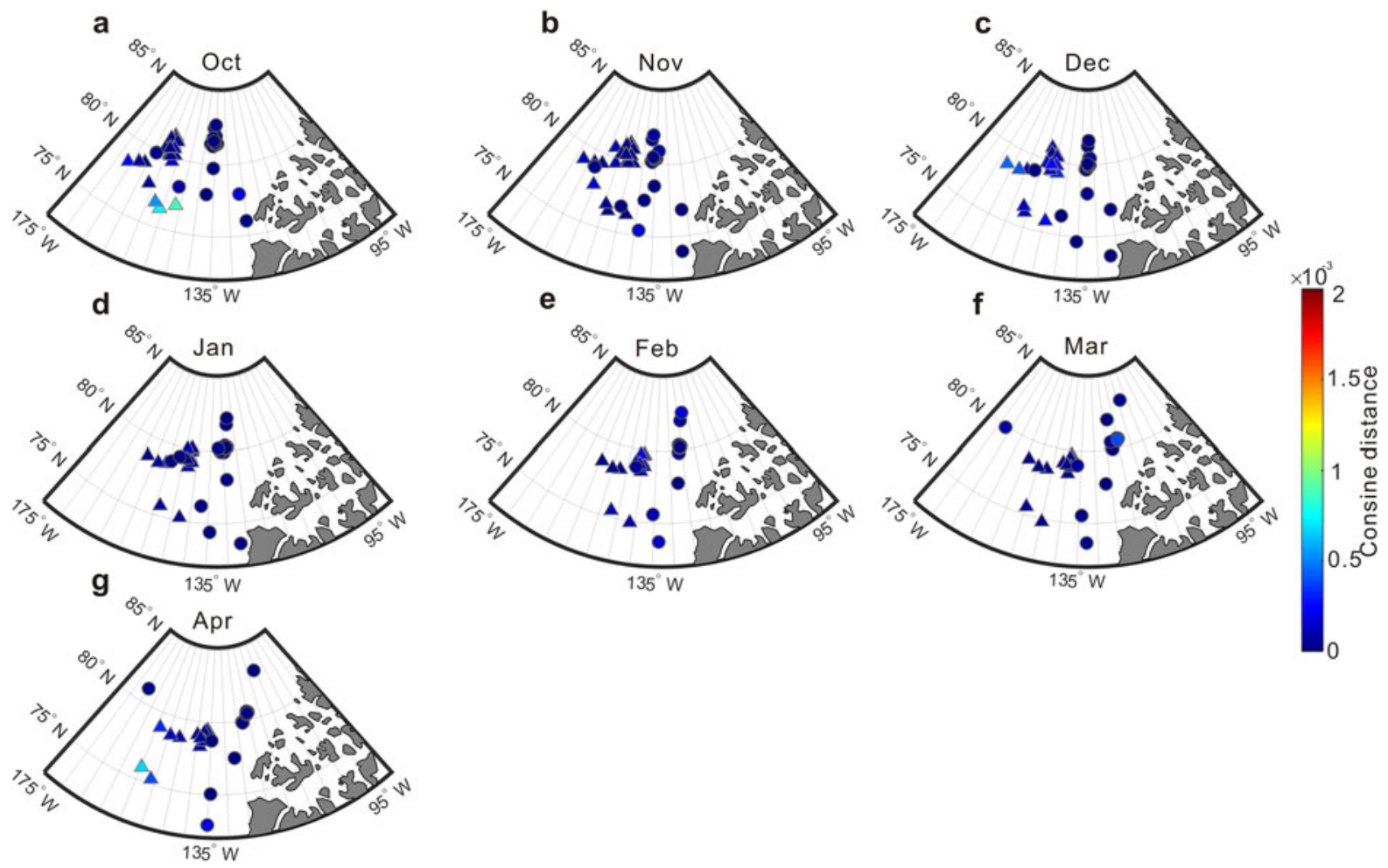

Fig. 9. Same as Figure 8, but for OSI-SAF. 

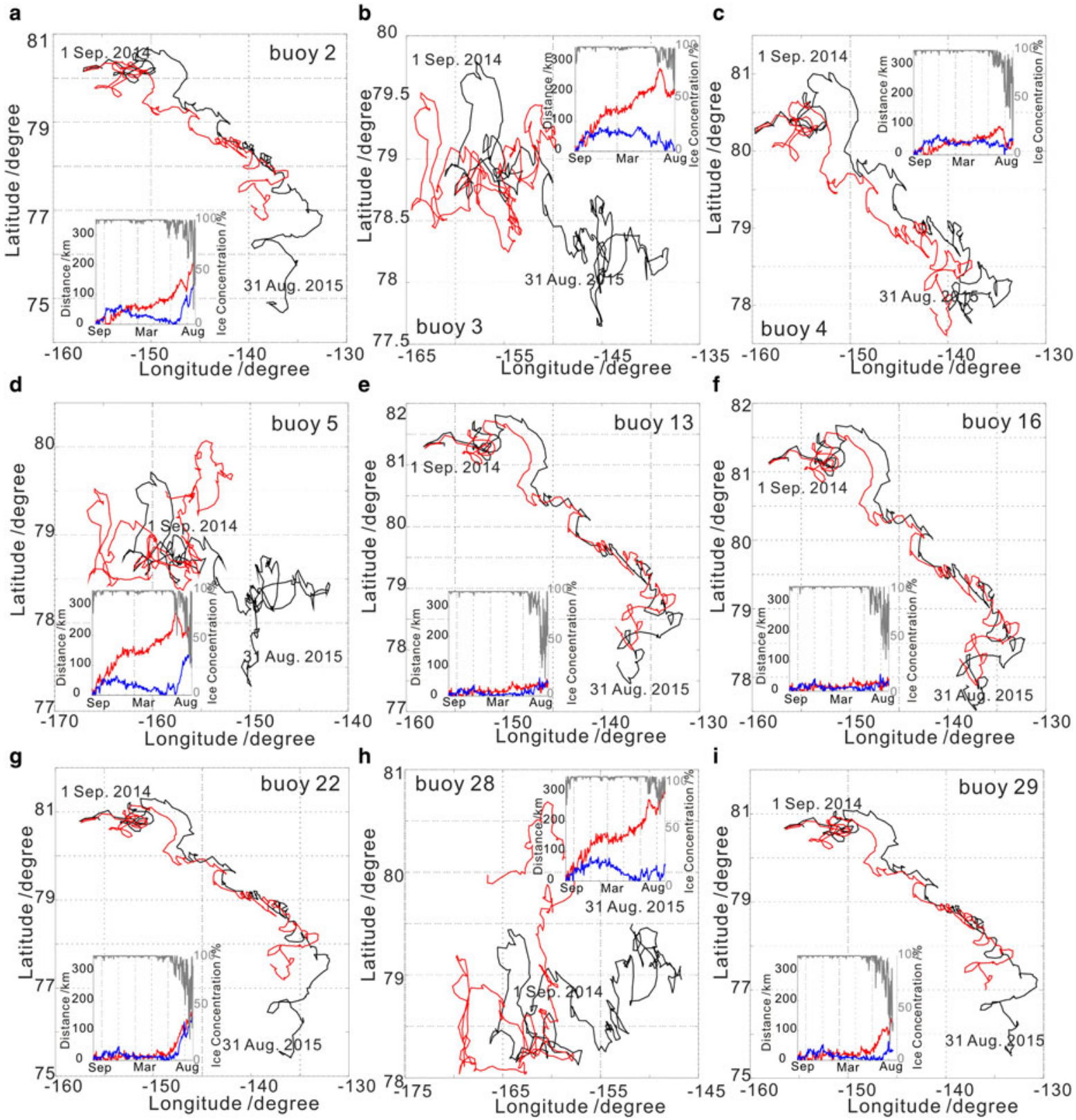

Fig. 10. (a-i) Drifter trajectories (black line) and reconstructed trajectories from NSIDC (red line) during 2014/15. Subplots show Euclidean distance between NSIDC and drifter trajectories in zonal (red line) and meridional (blue line) directions, and time series of sea-ice concentration (gray line) along drifter trajectories.

for locations near Banks Island. In summer 2016, the spatial variations of Euclidean distance were moderate (Figs $6 \mathrm{j}-1$ ); however, there were large variations in cosine distance (Figs $8 j-1$ ), especially for the two drifters north of $80^{\circ} \mathrm{N}$. After long-distance poleward drift, their cosine distance was two orders of magnitude larger than that of drifters at lower latitudes, indicating that despite reasonable estimates of drift distance, estimated drift orientation could deviate from or even be opposite to sea-ice drift orientation in the field. Similar to Euclidean distance, variation of cosine distance in OSI-SAF was relatively small and uniform (Fig. 9).

To evaluate the accuracy of reconstructed trajectories over periods exceeding 1 month, we reconstructed annual trajectories (from 1 September to 31 August of the subsequent year) using NSIDC data in 2014/15 and 2016/17 (Figs 10, 11). In 2014/15, reconstructed trajectories matched well with trajectories of drifters 13 and 16 (Figs 10e, f) with maximum Euclidean distances of 57 and $47 \mathrm{~km}$ in the zonal and meridional directions. For drifters 4, 22 and 29, the NSIDC product could reconstruct a near-realistic spatial relationship (Figs 10c, g, i) with maximum Euclidean distances of 95, 171 and $141 \mathrm{~km}$, respectively. Zonal displacements reconstructed from NSIDC deviated considerably from those of drifters 3, 5 and 28 (Figs 10b, d, h); net reconstructed zonal displacement was larger than net reconstructed meridional displacement, indicating considerable underestimation of zonal drift speed. Drifters 3, 5 and 28 encountered ice concentrations of $<83 \%$ during the first few days of September, while the other drifters encountered sea-ice concentration of larger than $95 \%$ throughout September. As a result, we infer that initial sea-ice conditions might have an impact on the estimation of sea-ice drift, and NSIDC is able to reconstruct trajectories that are dominated by meridional drift with less meander (e.g. drifters 13 and 16).

The situation was different in 2016/17 (Fig. 11). There was poor agreement between reconstructed and drifter trajectories. Reconstructed trajectories only narrowly approximated trajectories of drifters 19 and 22 (Figs 11d, e) with maximum Euclidean distances of 314 and $302 \mathrm{~km}$, which exceeded twice the maximum Euclidean distances of drifters 3, 5 and 28 in 2014/15. Except for drifters 19 and 22, mean sea-ice concentration in September along drifter 

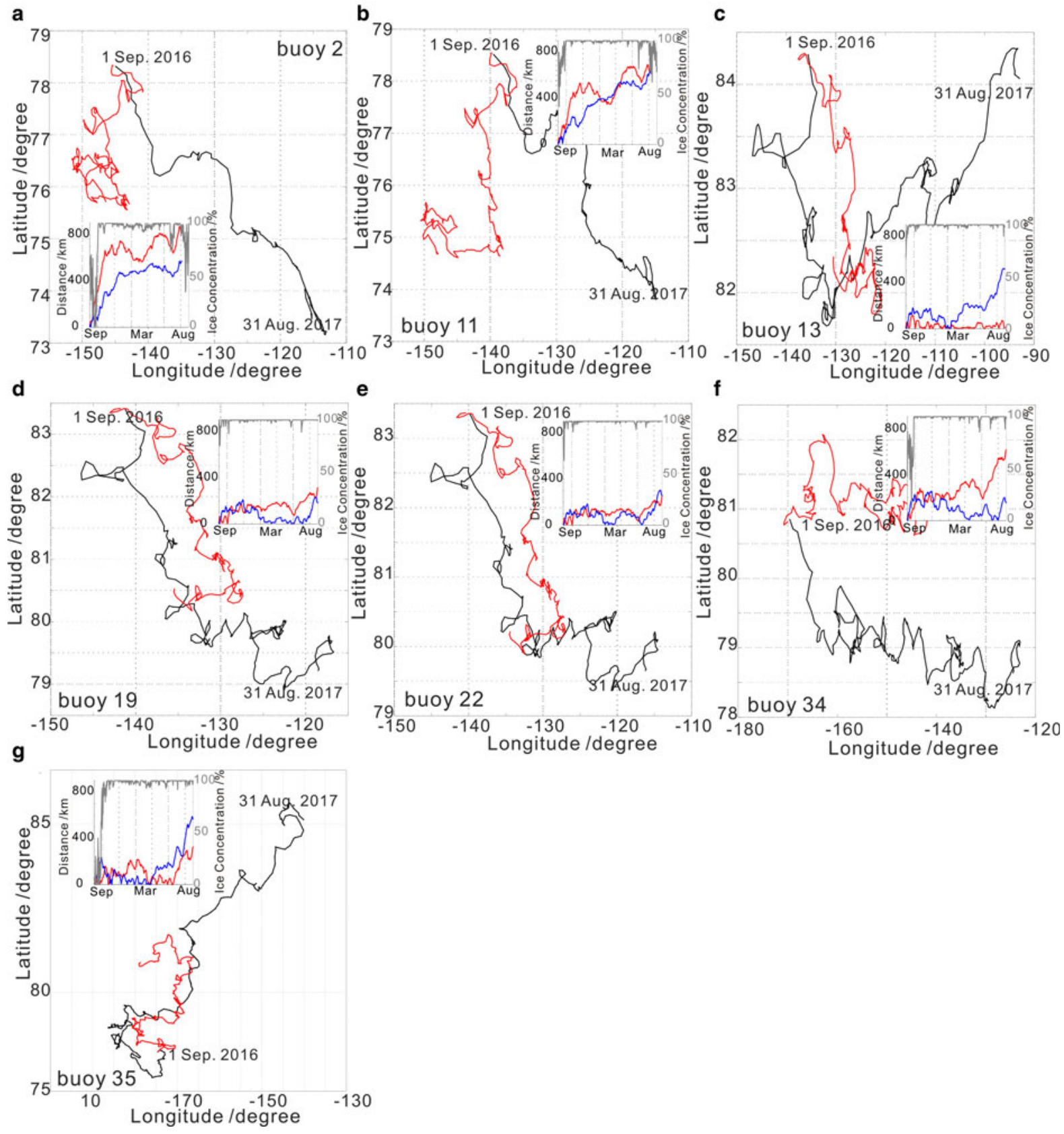

Fig. 11. Same as Figure 10, but for 2016/17.

trajectories was $<80 \%$, and drifters 2 and 35 even traveled close to open water for a few days. Even though meridional drift was reasonably reconstructed by NSIDC, low ice concentration renders estimation of sea-ice drift even more difficult because ice motion in NSIDC product is valid only for areas where ice concentration exceeds $15 \%$. Variability of the distance between reconstructed and drifter trajectories in 2014/15 and 2016/17 indicates that uncertainties caused by the sea-ice conditions in September influence the accuracy of reconstructed trajectories at the beginning of the trajectories; this influence dominates in the subsequent months; error accumulates over time, resulting in very large distances between the final positions in reconstructed and drifter trajectories.

\section{Feasibility of using sea-ice motion products to characterize sea-ice deformation}

Sea-ice deformation could be quantified by estimating the differential kinematic properties of ice motion (e.g. Hutchings and Hibler,
2008; Rampal and others, 2008; Lukovich and others, 2011). Therefore, it is essential to determine the distance between ice-floe pairs accurately for the estimation of ice deformation rate. Here, we calculated relative error of the distance between two arbitrary positions as estimated from sea-ice motion products relative to drifter data for different sampling intervals. Spatial scaling characteristics of the error were then obtained from the paired points for different distances (Fig. 12). For the data from 2014/15 and 2016/17, we found notable seasonal variation and scale dependence in the relative errors of both NSIDC and OSI-SAF products. Mean relative error decreases with increasing spatial scale, especially in warmer seasons. For distances estimated at different time intervals, relative errors are similar and accuracies tend to be comparable. The smallest relative errors were found at scales larger than $1000 \mathrm{~km}$, and relative errors ranged from 0.2 to $3.9 \%$ for NSIDC and 0.6 to $2.3 \%$ for OSI-SAF. This indicates that the NSIDC and OSI-SAF products are more adapted to provide estimates of sea-ice deformation at coarser spatial resolution than at small scales. 


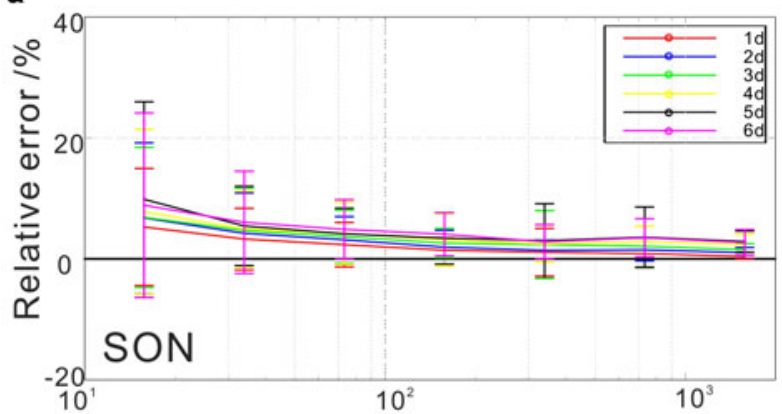

b

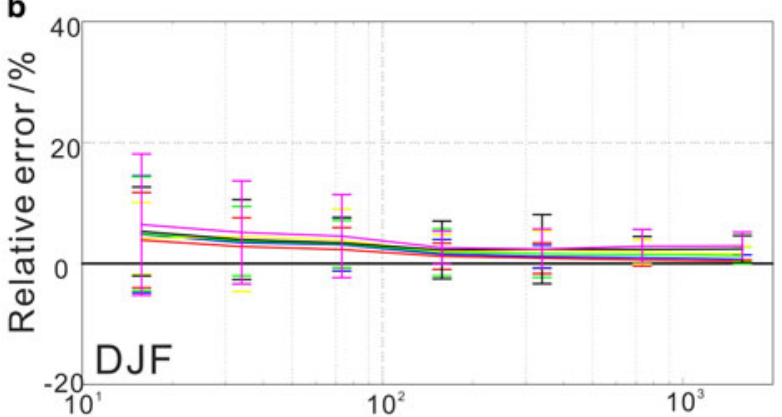

C

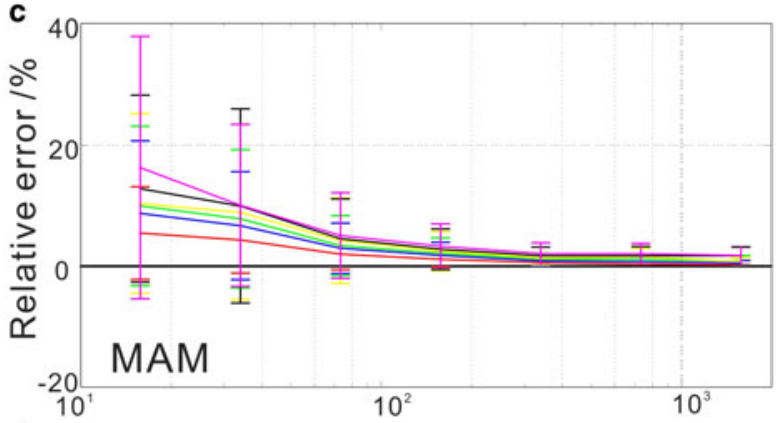

d

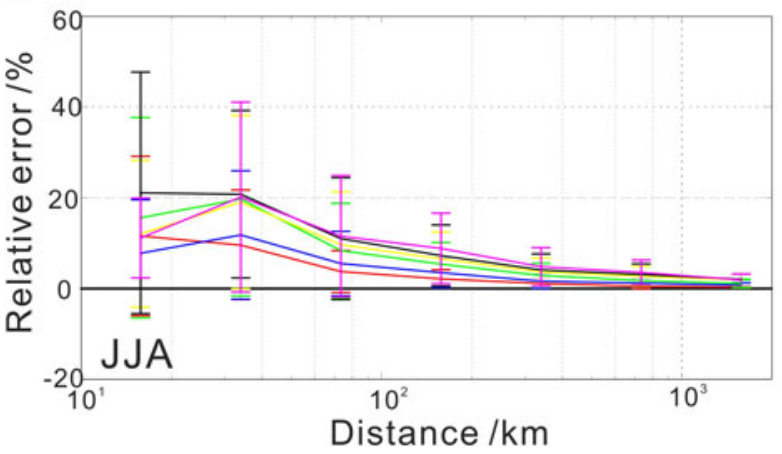

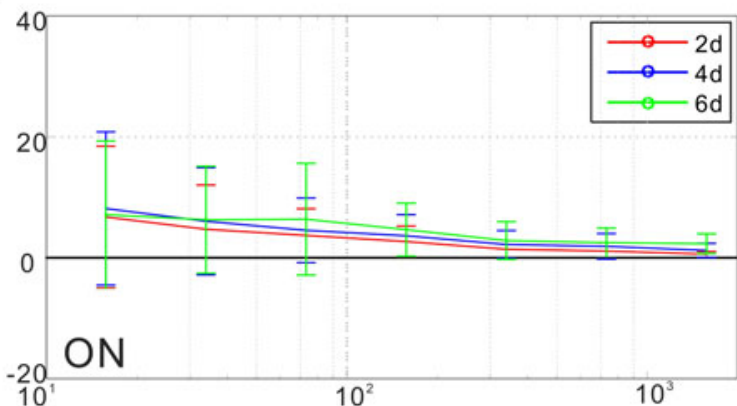

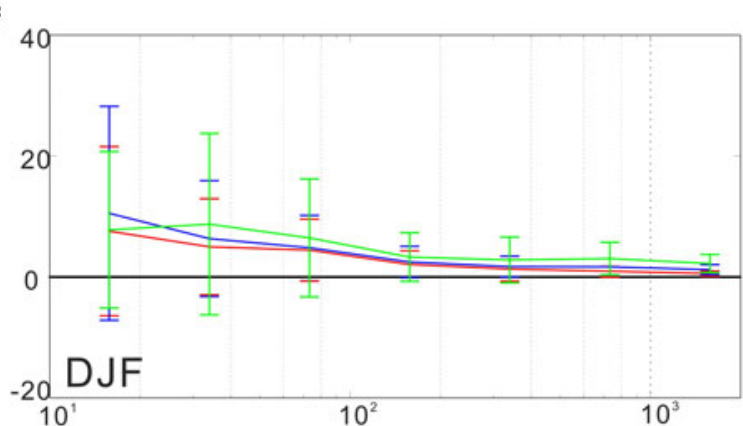

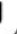

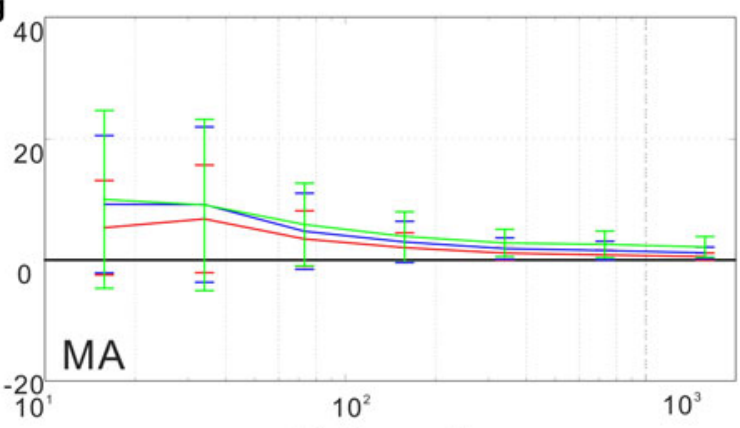

Distance / km

Fig. 12. Mean and std dev. of relative error of Euclidean distance between two arbitrary points as estimated (a-d) from the NSIDC product and (e-g) from the OSI-SAF product relative to drifter data for different sampling intervals and seasons.

For NSIDC, at the scale $<100 \mathrm{~km}$, relative errors at different time intervals show large seasonal variations. However, compared with distance estimated at other intervals, distance estimated at 1 $\mathrm{d}$ interval is always the most accurate and has smaller variations. Maximum relative error at the $1 \mathrm{~d}$ interval is $11.6 \%( \pm 17.6 \%)$ in summer at the scale of $10-15 \mathrm{~km}$. Minimum relative error at the $1 \mathrm{~d}$ interval is identified in winter; it ranges from 0.36 to $3.9 \%$ for different spatial scales. At the scale of $10-15 \mathrm{~km}$, minimum relative errors of distance estimated from NSIDC are $5.3 \%( \pm 9.7 \%), 3.8 \%( \pm 7.8 \%), 5.5 \%( \pm 7.6 \%)$ and $11.6 \%( \pm 17.6 \%)$ for autumn, winter, spring and summer, respectively. When the scale increases to $15-25 \mathrm{~km}$, relative error decreases accordingly to $3.3 \%( \pm 5.0 \%)$ in autumn, $2.8 \%( \pm 4.7 \%)$ in winter, $4.3 \%$ $( \pm 5.5 \%)$ in spring and $9.5 \%( \pm 12.1 \%)$ in summer. At the scale of $25-62.5 \mathrm{~km}$, which is just larger than one pixel of the NSIDC product, relative errors in autumn, winter, spring and summer are $2.3 \%( \pm 3.7 \%), 2.3 \%( \pm 3.6 \%), 2.0 \%( \pm 2.5 \%)$ and $3.8 \%$ $( \pm 4.6 \%)$, respectively. This indicates that std dev. and seasonal variabilities of distance estimates at the sub-pixel scale are larger than those at the scale of over $25 \mathrm{~km}$.

Since OSI-SAF operates during freezing seasons, there is moderate variation in relative error with time interval. As expected, compared with distances estimated at 4 and $6 \mathrm{~d}$ intervals, distance estimated at $2 \mathrm{~d}$ interval is the most accurate. At the scale of $25-$ $62.5 \mathrm{~km}$, relative error at the $2 \mathrm{~d}$ interval is $3.7 \%( \pm 4.4 \%), 4.4 \%$ $( \pm 5.1 \%)$ and $3.5 \%( \pm 4.6 \%)$ in autumn, winter and spring, respectively. In comparison, relative errors at the $2 \mathrm{~d}$ interval of the NSIDC product are smaller; they are $3.2 \%( \pm 3.8 \%)$ in autumn, $3.1 \%( \pm 4.3 \%)$ in winter and $2.9 \%( \pm 4.2 \%)$ in spring. At the scale of $62.5-100 \mathrm{~km}$, relative errors in OSI-SAF are larger than 

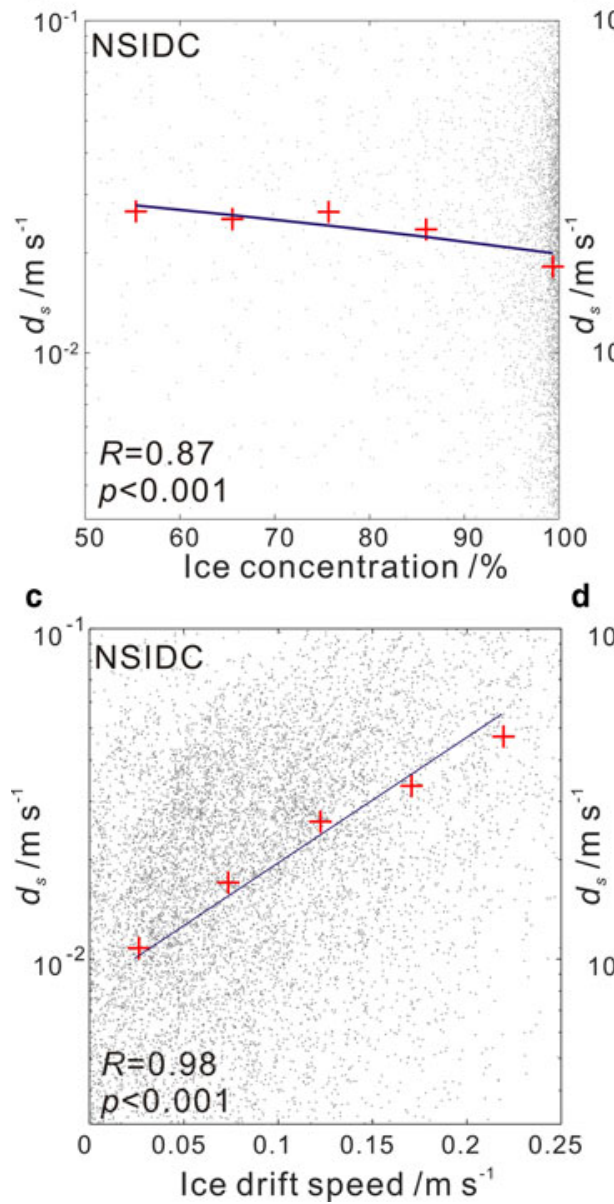

b
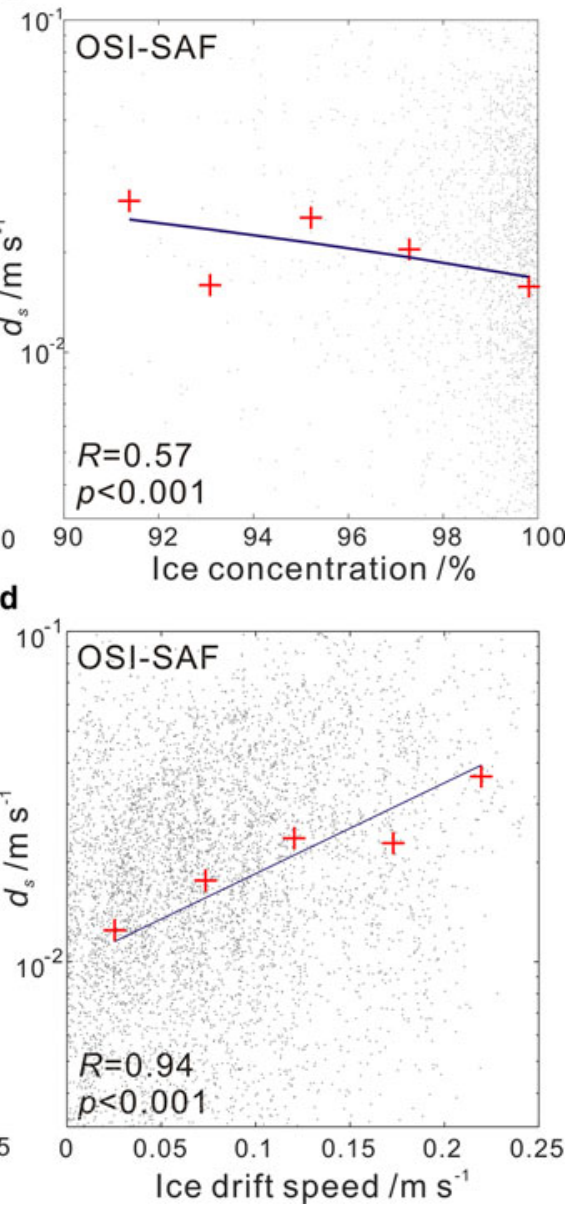

Fig. 13. Scatterplots between ( $a$ and $b$ ) sea-ice concentration and absolute error of sea-ice drift speed $\left(d_{s}\right)$ derived from NSIDC and OSI-SAF, and between ( $c$ and $d$ ) ice drift speed and absolute error of sea-ice drift speed $\left(\mathrm{d}_{\mathrm{s}}\right)$ derived from NSIDC and OSI-SAF. Red crosses denote mean absolute errors for different bins of sea-ice concentration and ice drift speed, and blue line denotes the result of linear regression analysis. those in NSIDC; autumn, winter and spring values of OSI-SAF are $2.6 \%( \pm 2.6 \%), 2.1 \%( \pm 2.3 \%)$ and $2.0 \%( \pm 2.5 \%)$, and are $1.9 \%( \pm 2.8 \%), 1.5 \%( \pm 2.4 \%)$ and $1.8 \%( \pm 2.1 \%)$ for NSIDC. The performance of OSI-SAF in distance estimation is lower than that of NSIDC. The ability of sea-ice motion products to characterize sea-ice deformation has been verified by the performance of sea-ice products to estimate distances between ice-floe pairs, and could be used to fulfill the needs of sea-ice deformation observations at meso- and even larger scales, especially for quantifying long-term changes because of the long-time series for both NSIDC and OSI-SAF products. However, there are relatively large uncertainties in both the NSIDC and OSI-SAF products at sub-pixel scales. Therefore, it is still necessary to derive sea-ice motion products from high-resolution remote-sensing data such as high-resolution SAR (e.g. Kwok, 2006). Remote-sensing ice motion products are also unable to capture high-frequency intraday sea-ice deformations, which dominate over the ice deformation spectrum because of the intermittency of ice dynamics (e.g. Lei and others, 2020).

\section{Discussion}

There were extreme differences in summer sea-ice conditions in our study area between 2014 and 2016 (Lei and others, 2020). We quantified the influence of sea-ice concentration on the absolute error of sea-ice drift speed derived from ice motion products (Figs 13a, b). To ensure sufficient samples under different sea-ice conditions, we divided sea-ice concentrations into five bins from 50 to $100 \%$ for the NSIDC product, and five bins from 90 to $100 \%$ for the OSI-SAF product. Statistically significant results from linear regression analysis verify the relationship between absolute error and ice concentration at daily and monthly (e.g. Sumata and others, 2014) scales for both NSIDC and OSI-SAF. With sea-ice concentrations of $50-100 \%$, the absolute error of the NSIDC product ranged from 0.018 to $0.027 \mathrm{~m} \mathrm{~s}^{-1}$. With ice concentrations of over $90 \%$, the absolute error of the OSI-SAF product ranged from 0.016 to $0.029 \mathrm{~m} \mathrm{~s}^{-1}$, but correlation coefficient was relatively low, which is related to insufficient samples in bins at low concentrations.

A similar analysis was performed to quantify the influence of ice drift speed on the absolute error of ice drift speed derived from sea-ice motion products (Figs 13c, d). Five bins of ice drift speed were defined, and linear regression was conducted between ice drift speed and mean absolute error of sea-ice speed for different bins. Absolute errors of sea-ice speed from NSIDC and OSI-SAF products both demonstrated statistically significant $(p<0.001)$ linear relationships with ice drift speed, and their correlation coefficients $(R)$ both exceeded 0.9. This indicates the absolute errors of sea-ice speed from both products have a strong dependence on the magnitude of ice drift speed. When ice drift speed ranges from 0 to $0.25 \mathrm{~m} \mathrm{~s}^{-1}$, the absolute error of ice speed from NSIDC ranges from 0.01 to $0.047 \mathrm{~m} \mathrm{~s}^{-1}$, and the corresponding absolute error of ice speed from OSI-SAF ranges from 0.012 to $0.036 \mathrm{~m} \mathrm{~s}^{-1}$. Compared with OSI-SAF product, NSIDC could better estimate sea-ice drift speed with the magnitude of speed lower than $0.1 \mathrm{~m} \mathrm{~s}^{-1}$. However, the absolute error of ice speed from NSIDC increases $10-40 \%$ when ice drift speed increases to $0.1-0.25 \mathrm{~m} \mathrm{~s}^{-1}$, which is larger than that from OSI-SAF. This implies that the accuracy of sea-ice speed estimation for NSIDC product is lower for high-speed sea ice.

Active cyclones were observed in September 2016, and enhanced wind speed in the vicinity of the drifters as well as the speed of sea ice (Lei and others, 2020). Combined with lower compactness of the 
sea-ice cover, the remarkably enhanced ice drift speed in September 2016 leads to a partial increase in the uncertainty for the NSIDC ice motion product compared to that in September 2014.

\section{Conclusions}

In this study, two widely used sea-ice motion products from NSIDC and OSI-SAF were validated with data collected by ice drifters that were deployed during CHINARE cruises in the summers of 2014 and 2016 in the western Arctic Ocean. The 2-yearlong dataset allowed us to quantify seasonal and regional variations of the accuracy of sea-ice motion products. For sea-ice drift speed, estimates from both NSIDC and OSI-SAF products exhibited good agreement with drifter data. The NSIDC product underestimated daily sea-ice drift speed with relative errors of -2 and $-0.6 \%$ for the freezing seasons of $2014 / 15$ and 2016/17, respectively; relative errors increased to $-10 \%(2014 / 15)$ and $-7.2 \%(2016 / 17)$ for the melt seasons. In contrast, OSI-SAF overestimated sea-ice drift at $2 \mathrm{~d}$ sampling interval with relative errors of $12 \%(2014 / 15)$ and $4 \%(2016 / 17)$. However, compared with sea-ice drift speed obtained from sub-daily drifter positions, ice speed estimates from NSIDC and OSI-SAF are underestimated. Monthly mean absolute error of ice speed from NSIDC varied spatially, with larger values in the MIZ than in the PIZ.

We reconstructed Lagrangian trajectories over a temporal window of 1 month using the NSIDC and OSI-SAF products, and calculated Euclidean distance and cosine distance between reconstructed and drifter trajectories to quantify the magnitude of deviation and geometrical similarity between trajectories. There was larger seasonal variability in the Euclidean distance between NSIDC and drifter trajectories than that of OSI-SAF. Spatial variability of Euclidean distance and cosine distance was generally larger at lower latitudes, which indicated spatial heterogeneity in NSIDC sea-ice drift estimates. Initial ice conditions influence the accuracy of reconstructed trajectories at the initial stage; error accumulates over time, resulting in large uncertainties in NSIDC drift speed estimates over 1 month. Nevertheless, the OSI-SAF and NSIDC products are still adequate for reconstructing sea-ice advection at a monthly scale. However, the influence of sea-ice concentration, coastal constraint and seasonality need to be taken into consideration.

The feasibility of using the NSIDC and OSI-SAF products to characterize sea-ice deformation was assessed by evaluating the relative error of the distance between two arbitrary positions as estimated by sea-ice motion products relative to drifter data for different sampling intervals, and its variation with spatial scale. Relative error decreases with increased distance imply that ice deformation estimates from remote-sensing products are acceptable at coarser scales. As a result of better spatial resolution, distances estimated from NSIDC are more accurate than those from OSI-SAF for the same time interval and period. The NSIDC and OSI-SAF products can be used for data assimilation or verification of numerical model output. However, their ability to characterize sea-ice deformation is limited by their coarse temporal and spatial resolutions because of the intermittency and localization of sea-ice dynamics.

Acknowledgements. This work was supported by the National Key Research and Development Program of China (2018YFA0605903 and 2016YFC14003) and the National Natural Science Foundation of China (41976219/41722605). J.H. is funded by the United States National Science Foundation (OPP 1722729 and OPP 1740768).

\section{Author contributions.}

R.L. conducted in situ drifter deployment. G.Z. and R.L. gathered and preprocessed drifter data. D.G., R.L. and J.H. carried out the experiment and analysis. D.G., R.L., J.H., M.Z. and X.P. were involved in conceiving and writing the manuscript.

\section{References}

Hutchings JK and Hibler III WD (2008) Small-scale sea ice deformation in the Beaufort Sea seasonal ice zone. Journal of Geophysical Research: Oceans 113(C8), C08032. doi: 10.1029/2006JC003971.

Hwang B (2013) Inter-comparison of satellite sea ice motion with drifting buoy data. International Journal of Remote Sensing 34(24), 8741-8763. doi: 10.1080/01431161.2013.848309.

Jackson K and 6 others (2013) A novel and low-cost sea ice mass balance buoy. Journal of Atmospheric and Oceanic Technology 30(11), 2676-2688. doi: 10.1175/JTECH-D-13-00058.1.

Kimura N, Nishimura A, Tanaka Y and Yamaguchi H (2013) Influence of winter sea-ice motion on summer ice cover in the Arctic. Polar Research 32(1), 20193. doi: 10.3402/polar.v32i0.20193.

Krumpen T and 7 others (2016) Recent summer sea ice thickness surveys in Fram Strait and associated ice volume fluxes. The Cryosphere 10(2), 523-534. doi: 10.5194/tc-10-523-2016.

Kwok R (2006) Contrasts in sea ice deformation and production in the Arctic seasonal and perennial ice zones. Journal of Geophysical Research: Oceans 111(C11), C11S22. doi: 10.1029/2005JC003246.

Kwok R (2009) Outflow of Arctic Ocean sea ice into the Greenland and Barents Seas: 1979-2007. Journal of Climate 22(9), 2438-2457. doi: 10. 1175/2008JCLI2819.1.

Kwok R (2010) Satellite remote sensing of sea-ice thickness and kinematics: a review. Journal of Glaciology 56(200), 1129-1140. doi: 10.3189/ 002214311796406167.

Lavergne T, Eastwood S, Teffah Z, Schyberg H and Breivik L A (2010) Sea ice motion from low-resolution satellite sensors: an alternative method and its validation in the Arctic. Journal of Geophysical Research: Oceans 115 (C10), C10032. doi: 10.1029/2009JC005958.

Lei $\mathbf{R}$ and 5 others (2016) Characterization of sea ice kinematic in the Arctic outflow region using buoy data, Polar Research 35(1), 22658. doi: 10.3402/ polar.v35.22658.

Lei $\mathbf{R}$ and 6 Others (2017) Characterization of summer Arctic sea ice morphology in the $135^{\circ}-175^{\circ} \mathrm{W}$ sector using multi-scale methods. Cold Regions Science and Technology 133, 108-120. doi: 10.1016/j.coldregions.2016.10.009.

Lei R, Gui D, Heil P, Hutchings JK and Ding M (2020) Comparisons of sea ice motion and deformation, and their responses to ice conditions and cyclonic activity in the western Arctic Ocean between two summers. Cold Regions Science and Technology 170, 102925. doi: 10.1016/j.coldregions. 2019.102925 .

Lindsay RW and Stern HL (2003) The RADARSAT geophysical processor system: quality of sea ice trajectory and deformation estimates. Journal of Atmospheric and Oceanic Technology 20(9), 1333-1347. doi: 10.1175/ 1520-0426(2003)020<1333:TRGPSQ >2.0.CO;2.

Lukovich JV, Babb DG and Barber DG (2011) On the scaling laws derived from ice beacon trajectories in the southern Beaufort Sea during the International Polar Year - Circumpolar Flaw Lead study, 2007-2008. Journal of Geophysical Research: Oceans 116(C9), C00G07. doi: 10.1029/ 2011JC007049.

Magdy N, Sakr MA, Mostafa T and El-Bahnasy K (2015) Review on trajectory similarity measures. IEEE Seventh International Conference on Intelligent Computing and Information Systems (ICICIS), 12-14 December 2015, Cairo, Egypt. IEEE, pp. 613-619. doi: 10.1109/IntelCIS.2015.7397286.

Moore GWK, Schweiger A, Zhang J and Steele M (2018) Collapse of the 2017 winter Beaufort high: a response to thinning sea ice? Geophysical Research Letters 45(6), 2860-2869. doi: 10.1002/2017GL076446.

Nakamura T, Taki K, Nomiya H, Seki K and Uehara K (2013) A shape-based similarity measure for time series data with ensemble learning. Pattern Analysis and Applications 16(4), 535-548. doi: 10.1007/ s10044-011-0262-6.

Nguyen AT, Menemenlis D and Kwok R (2011) Arctic Ice-ocean simulation with optimized model parameters: approach and assessment. Journal of Geophysical Research: Oceans 116, C04025. doi: 10.1029/2010JC006573.

Olason E and Notz D (2014) Drivers of variability in Arctic sea-ice drift speed. Journal of Geophysical Research: Oceans 119(9) 5755-5775. doi: 10.1002/2014JC009897.

Peeken I and 8 others (2018) Arctic Sea ice is an important temporal sink and means of transport for microplastic. Nature Communications 9(1), 1-12. doi: 10.1038/s41467-018-03825-5.

Petty AA and 6 others (2018) The Arctic sea ice cover of 2016: a year of record-low highs and higher-than-expected lows. The Cryosphere 12(2), 433-452. doi: 10.5194/tc-12-433-2018. 
Pfirman SL, Colony R, Nürnberg D, Eicken H and Rigor I (1997) Reconstructing the origin and trajectory of drifting Arctic sea ice. Journal of Geophysical Research: Oceans 102(C6), 12575-12586. doi: 10.1029/ 96JC03980.

Rampal P, Bouillon S, Ólason E and Morlighem M (2016) neXtSIM: a new Lagrangian sea ice model. The Cryosphere 10, 1055-1073. doi: 10.5194/ tc-10-1055-2016

Rampal P, Weiss J, Marsan D, Lindsay R and Stern H (2008) Scaling properties of sea ice deformation from buoy dispersion analysis. Journal of Geophysical Research: Oceans 113(C3), C03002. doi: 10.1029/2007JC004143.

Richter-Menge JA and 5 others (2006) Ice mass-balance buoys: a tool for measuring and attributing changes in the thickness of the Arctic sea-ice cover. Annals of Glaciology 44, 205-210. doi: 10.3189/172756406781811727.

Rigor IG, Wallace JM and Colony RL (2002) Response of sea ice to the Arctic Oscillation. Journal of Climate 15(18), 2648-2663. doi: 10.1175/1520-0442 (2002)015<2648:ROSITT>2.0.CO;2.

Rollenhagen K, Timmermann R, Janjić T, Schröter J and Danilov S (2009) Assimilation of sea ice motion in a finite-element sea ice model. Journal of
Geophysical Research: Oceans 114(C5), C05007. doi: 10.1029/ 2008JC005067.

Rozman P and 7 others (2011) Validating satellite derived and modelled sea-ice drift in the Laptev Sea with in situ measurements from the winter of 2007/ 2008. Polar Research 30(1), 7218. doi: 10.3402/polar.v30i0.7218.

Spreen G, Kaleschke L and Heygster G (2008) Sea ice remote sensing using AMSR-E $89 \mathrm{GHz}$ channels. Journal of Geophysical Research: Oceans 113 (C2), C02S03. doi: doi:10.1029/2005JC003384.

Sumata $\mathbf{H}$ and 7 others (2014) An intercomparison of Arctic ice drift products to deduce uncertainty estimates. Journal of Geophysical Research: Oceans 119(8), 4887-4921. doi: 10.1002/2013JC009724.

Tilling RL, Ridout A and Shepherd A (2018) Estimating Arctic sea ice thickness and volume using CryoSat-2 radar altimeter data. Advances in Space Research 62(6), 1203-1225. doi: 10.1016/j.asr.2017.10.051.

Tschudi M, Meier WN, Stewart JS, Fowler C and Maslanik J (2019) Polar Pathfinder Daily $25 \mathrm{~km}$ EASE-Grid Sea Ice Motion Vectors, Version 4. Boulder, Colorado USA. NASA National Snow and Ice Data Center Distributed Active Archive Center. doi: 10.5067/INAWUWO7QH7B. 